ARoueología Y SociedAd

NNo 26, 2013: 45-70

ISSN: 0254-8062

RECIBIDO: 6/MAR. / 2013

ACEPTADO: 10 / ABR. / 2013

\title{
SINCRETISMO MITOLÓGICO INDUCIDO POR CONTACTO
}

\author{
JORGE GÓMEZ RENDÓN PH.D. \\ UNIVERSITEIT VAN AMSTERDAM \\ j.a.gomezrendon@uva.nl
}

\begin{abstract}
¿Por qué los seres humanos construimos mitos? ¿Por qué tienen los significados que tienen? ¿Por qué a los seres humanos les importa tanto compartir sus mitos? ¿Qué hay en los mitos que atrae tan fuertemente a los seres humanos que les hace considerarlos sagrados? Creo que la respuesta a todas estas preguntas es porque los mitos cumplen funciones vinculadas, y porque contienen niveles de significado que alcanzan una correspondencia experimentada intuitivamente, porque los mitos son narrativas que tienen una estructura anclada en el tiempo, porque tratan simultáneamente de cosas importantes tanto en lo social como en lo psicológico, porque utilizan lo percibido y disponible y lo vinculan al sentido primordial en un nivel más profundo de la realidad, a ello se debe que tengan el poder que justificadamente les atribuimos en algunas sociedades.
\end{abstract}

(Cohen 1969: 351).

\section{RESUMEN}

El presente estudio explora un aspecto olvidado del análisis mitológico estructuralista, según el cual el mito es una matriz narrativa que puede y debe ser leída en un eje diacrónico. Esta perspectiva ilumina los aspectos histórico-sociales de la mito-poesis tal como se reflejan en la materia y la forma de los mitos. Luego de proponer un modelo complementario al análisis estructuralista tradicional, se instrumenta el mismo a través de un estudio comparativo de la mitología andoa y sus relaciones con otras mitologías de pueblos vecinos del alto Amazonas.

Palabras ClaVE: Mitología, sincretismo, contacto, andoa, estructuralismo, mitemas.

\section{AbSTRACT}

The present study explores an almost untrodden field in the structuralist mythemic analysis, according to which a myth is a narrative matrix that may and should be read along a diachronic axis. This perspective highlights socio-historical aspects of mythopoesis as mirrored on the matter and pattern of myths. An analytic proposal complementing traditional structuralist analysis is developed through a comparative study of Andoan and other mythologies from the Upper Amazon basin.

KEYwORDS: Mythology, syncretism, contact, Andoa, structuralism, mytheme 


\section{INTRODUCCIÓN: EL MITO MÁS ALLÁ DEL PENSAMIENTO ESTRUCTURALISTA}

Con todas las virtudes de un método maduro y sistemático, el análisis estructural del mito inaugurado y llevado a su máxima expresión por el antropólogo francés Lévi-Strauss $(1955,1964,1967,1968,1971)$ tuvo como consecuencia el desplazamiento de una serie de aspectos del mito que tienen que ver con su funcionalidad sociohistórica, es decir, con el papel que cumple como forma particular de un discurso que (re)produce la realidad social y que es (re)producido por dicha realidad.

El análisis mitológico en cuanto herramienta del pensamiento estructuralista se ocupó exclusivamente de encontrar en los mitos aquella evidencia que sustentara la idea de que todos los seres humanos tenemos categorías de pensamiento sobre las que organizamos la realidad, basadas mayormente en oposiciones de tipo binario. Al hacerlo olvidó que el mito como tipo de discurso es una construcción socializada e histórica.

Cuando asumimos la narrativa mitológica como discurso, nos vemos abocados a reconocer su triple naturaleza, tal como se expresa en tres aspectos que lejos de ser excluyentes se complementan. Cada aspecto de esta naturaleza corresponde a un 'nivel de significado', como insiste el epígrafe inicial (Cohen 1969: 351). Estos niveles de significado son, sin orden de importancia: el cognoscitivo, del cual tiene mucho que decirnos el análisis estructuralista; el social, con una perspectiva temporal que involucra la historia de constitución del discurso mítico; y el comunicativo, materia de una teoría socio-semiótica que entiende el mito como un macroacto de habla con una función poética de la identidad del grupo portador.

El propósito de la presente investigación es instrumentar en el análisis esta concepción tripartita del mito a partir de un caso específico, la narrativa mitológica del pueblo andoano. Con este fin retomamos las herramientas básicas del análisis estructuralista y las refinamos con técnicas de la lingüística histórica y la lingüística de contacto -en particular-, la combinación de mitemas ${ }^{1}$ de diferente origen etnolingüístico en narrativas sincréticas a las cuales se han adaptado según una nueva sintaxis mitopoética. De esta manera buscamos desenredar el significado histórico y social del mito, no a partir de un análisis ingenioso de sus contenidos, sino de las relaciones de contacto interétnico que se reflejan en su composición y de la función identitaria que cumple en el presente.

Esta perspectiva ecléctica supone no sólo una concepción holística del mito como forma multifuncional de discurso sino también una divergencia del paradigma de análisis estructuralista. De acuerdo con esta perspectiva, cuando hablamos de elementos mitológicos semejantes en distintos grupos étnicos, asumimos que dicha semejanza se debe menos a categorías mentales que al contacto sociocultural entre dichos grupos. Una comparación con la historia de las lenguas y el cambio lingüístico es esclarecedora en este punto. Por ejemplo, una lengua como el castellano se parece a las lenguas que le dieron origen -el latín vulgar, el ibérico y el árabe- no porque comparta con ellas ciertos rasgos tipológicos universales cuanto porque es el resultado del contacto de dichas lenguas en unas circunstancias sociohistóricas específicas.

La consecuencia de lo expuesto hasta aquí es que, si la matriz de la mitopoesis, según el pensamiento estructuralista, está en la mente humana y sus procesos cognoscitivos, no puede describirse en términos temporales: por el contrario, desde nuestra perspectiva, la mitopoesis se desarrolla en la matriz dada por el contacto de los grupos humanos a través de la historia y la construcción de su identidad en el presente.

1 Adoptamos aquí sin mayor elaboración el concepto de 'mitema' tal como ha sido forjado en el análisis estructuralista, considerándolo como la unidad constitutiva mayor. Dicha unidad posee una relación que se expresa, en términos lógico-gramaticales, como «la asignación de un predicado a un sujeto» (Lévi-Strauss 1977: [1958]: 191). 


\section{EL CARÁCTER HISTÓRICO Y LA FUNCIÓN SOCIAL EN EL MITO}

El análisis de un corpus mitológico a lo largo de un eje temporal abarca dos dimensiones. La primera dimensión es de carácter diacrónico y comprende dos perspectivas. La primera perspectiva ilumina el proceso de producción verbal del mito (mito-poesis), que se despliega especialmente en el plano del significante, hablando en términos semióticos. La segunda perspectiva ilumina el proceso de significación del mito (mito-semiosis) ${ }^{2}$, que se desarrolla en el plano del significado. Así, mientras la primera perspectiva explica cómo se reorganizan los componentes del lenguaje mítico a través de la historia de contactos de un grupo humano con otros grupos, la segunda dilucida cómo los cambios en la estructura de contenido de un mito reflejan los cambios en la estructura social inducidos por el contacto. La segunda dimensión del análisis es de carácter sincrónico y tiene que ver con la manera en que un grupo utiliza el mito para dotar de significado y valor a su realidad social y al mismo tiempo marcar su identidad con respecto a otros grupos humanos en un momento de su historia.

Este interés nuestro en el aspecto temporal de los mitos no es nuevo y de él da cuenta incluso el mismo análisis estructuralista, cuando sostiene, a propósito de la transformación de los mitos, que éstos no desaparecen sino que toman cualquiera de dos rutas:

«[L]a de la elaboración novelesca y la de la reutilización con fines de legitimación histórica. Esta historia, a su vez, puede ser de dos tipos: retrospectiva, para fundar un orden tradicional en un lejano pasado, o prospectiva, para hacer de tal pasado el primordio de un porvenir que empieza a esbozarse» (Lévi-Strauss 1987: 253).

De acuerdo con lo expuesto, el mito tiene un carácter sociohistórico irrecusable tanto en la composición de sus elementos de forma como en la articulación de sus elementos de contenido, y en tal medida es posible rastrear en dicha composición y articulación señales de contacto entre el grupo portador del mito y otros con los cuales ha tenido relación a lo largo de su historia. Pero además, el mito cumple una función sociohistórica en la medida que se presenta como una suerte de código para interpretar la realidad presente de un grupo y marcar su distinción identitaria. Desde el punto de vista del análisis, su carácter sociohistórico lo convierte en una forma de registro, casi inconsciente diríamos, de los desarrollos históricos, al tiempo que su función sociohistórica le devuelve una agencia discursiva a partir de la cual re-crea el pasado y el presente del grupo que lo conserva y transmite. Esto implica que la mitopoesis tiene dos caras: una, mecánica, convencional e inconsciente; otra, creativa, arbitraria, consciente.

Si tomamos en cuenta lo dicho hasta aquí, no es una sorpresa que, estando hecho de palabras, el mito presente dos caras que se corresponden bien con lo que desde Saussure conocemos como langue y parole: porque si, por un lado, el lenguaje humano se compone de reglas y relaciones entre elementos que se despliegan de manera automática e inconsciente al hablar, por otro siempre se usa conscientemente para expresar según la manera particular de cada individuo. Aun así, la comparación no es del todo satisfactoria, pues la lengua es 'ahistórica' en el sentido de las reglas, mientras el mito es 'histórico'en el sentido de su estructura formal, y lo es precisamente porque es estructura materializada en un tiempo y un lugar específicos. En otras palabras, el mito es discurso. De ello se percató ya el mismo Lévi-Strauss cuando sostenía que «el aproximar el mito al lenguaje no resuelve nada: el mito integra la lengua; por el habla se lo conoce; pertenece al discurso» (Lévi-Strauss 1977 [1961]). Así, el mito es ese tercero que sin dejar de ser lenguaje, se ancla en la realidad que lo produce.

2 Mientras el término mito-poesis ha sido de uso frecuente desde los estudios de A. Potebnia y A. N. Veselovski, filólogos rusos decimonónicos antecesores de Propp (cf. Meletinski 2001: 114), el de mitosemiosis es de nuestra factura y se refiere con más especificidad al proceso de construcción de significado en el mito, distinto de la construcción poética del significante, que nosotros asociamos con la mito-poiesis propiamente dicha. 
Este anclaje del mito en la realidad social es doble (Ferraro 1977: 300). Si concebimos el mito como una totalidad sígnica compuesta por significante (elementos formales) y significado (elementos conceptuales), podemos trazar dos relaciones; una relación entre el significante del mito y la realidad social; y otra relación entre su significado y la misma realidad. La primera relación determina que el significante del mito sea cualquier elemento del mundo real, humano o natural, que pueda expresarse lingüísticamente: del mundo humano, por ejemplo, el ‘shamán' de los mitos kichwas de Pastaza, figura central del orden social; del mundo natural, el 'puma' de los mitos naporunas, especie endémica de las selvas amazónicas. La segunda relación, por su parte, exige que el significado del mito sea «el contenido profundo del discurso enunciado» (Ferraro 1977: 300, mi traducción), contenido que se teje siempre en una matriz ideológica que recoge relaciones de identidad y diferencia entre los grupos humanos. El corolario es que, si la realidad cambia, el mito puede cambiar tanto en su significante como en su significado. Dicho de otro modo, los significantes de un mito pueden cambiar si cambian los objetos del mundo que forman parte de la experiencia vital del grupo; este cambio puede ir de una transformación o un reemplazo a una desaparición completa. Del mismo modo, los significados del mito pueden cambiar si lo hace la ideología que los acuna, entendida ésta como conjunto de relaciones de identidad y diferencia que los grupos humanos construyen. Como veremos enseguida, el contacto entre dos o más grupos humanos desata precisamente los cambios y transformaciones en la realidad que activan los cambios y transformaciones en el mito. A propósito nos dice Amodio, en uno de los contados estudios que aborda la construcción de los mitos a partir del contacto sociocultural:

«Pasando de las funciones del mito a sus contenidos, parece suficientemente claro que los mitos cambian no sólo por presiones internas al contexto de una sociedad, sino también por contacto con otros grupos indígenas. Esta afirmación, tal vez obvia, nos permite considerar el mito como un elemento cultural dinámico, que es espejo de las complejas relaciones que los pueblos de una región determinada realizan entre ellos» (Amodio 1989: 92).

Este contacto supone la formación de un área cultural, de mayor o menor extensión, según sean los grupos que participen en ella. Para el caso que nos ocupa, el área cultural donde se encuentra el grupo cuyo corpus mitológico analizaremos es el noroccidente de la cuenca amazónica. Dentro de esta área hemos identificado a su vez una subárea, que Steward y Metraux (1948: 507) llaman «la montaña peruana y ecuatoriana» y que corresponde a la zona subandina selvática oriental. Por 'montaña' entienden ambos autores la vertiente oriental de los Andes, que corresponde al bosque tropical amazónico pero presenta a su vez una topografía accidentada y numerosos ríos torrentosos (Steward y Metraux 1948: 507). El Chuncho, como se llama también esta región, no sólo tiene la mayor diversidad lingüística de toda la cuenca amazónica (quince diferentes familias lingüísticas) sino que ha sido testigo de una larga historia de olas migratorias hacia la vertiente oriental andina. Ambos factores han incidido en un elevado número de contactos socioculturales entre los grupos a lo largo del tiempo. Las características etnográficas del área en cuestión se encuentran resumidas en Steward y Metraux (loc. cit.) y serán discutidas en la segunda parte de este estudio.

\section{LA MITO-POESIS Y LA MITO-SEMIOSIS INDUCIDA POR CONTACTO SOCIOCULTURAL}

En la sección anterior mostramos cómo el mito tomado como unidad sígnica compleja tiene como elementos un conjunto de significantes y otro de significados, los cuales corresponden al mundo de la experiencia sensible, tanto humana (sociedad) como física (naturaleza). Ahora bien, tanto sociedad como naturaleza experimentan cambios a través del tiempo, pero es el mundo de los seres humanos el que cambia con mayor rapidez comparado con la naturaleza, siendo incluso ahora más que nunca uno de los principales factores de cambio medioambiental. Se concluye, por lo tanto, que un cambio 
en el mundo social o natural conllevará un cambio en la materia prima de la mito-poesis y la mitosemiosis y producirá finalmente cambios en la forma y el contenido de los mitos.

¿Cuáles son los factores que producen cambios en el mundo natural y social? En primer lugar, el mundo natural cambia tanto por causas propias al desarrollo de los ecosistemas como por efecto de la acción humana: en el primer caso contamos, por ejemplo, alteraciones bruscas del medio por eventos catastróficos o cambios paulatinos de patrones meteorológicos; en el segundo están los daños antrópicos ocasionados al medio ambiente, como la tala indiscriminada de bosques y la consiguiente desaparición de especies vegetales y animales; también es posible, en este caso, que el desplazamiento geográfico (migración) de los grupos humanos, sin llevar implícito ningún daño medioambiental, conlleve un cambio de hábitat y por ende un cambio en la materia de la experiencia sensible de la que abrevan los mitos. Por su parte, los cambios del mundo social son mucho más complejos y dinámicos y una tipología exhaustiva de los mismos no compete al tema del presente estudio. No podemos dejar de mencionar empero los más comunes: uno de ellos es la ya mencionada migración, que no es otra cosa que el desplazamiento de los grupos humanos por agotamiento de recursos o por presiones de otros grupos; la conquista armada y el subsiguiente sometimiento de un grupo por parte de otro; las alianzas matrimoniales entre grupos exogámicos; las alianzas bélicas para hacer frente a grupos enemigos; los viajes periódicos para la obtención de recursos escasos en la propia región; y con más frecuencia que en el pasado, la desmembración grupal por factores externos generalmente imputables a estados u otras instituciones sociales hegemónicas de gran envergadura.

En cualquiera de los casos mencionados el efecto inmediato del cambio social se expresa en el contacto con otros grupos humanos. Es posible imaginar entonces al menos cuatro escenarios distintos: 1) los grupos que entran en contacto no conocían de su existencia ni habían estado en contacto en el pasado; 2) los grupos que entran en contacto conocían de su existencia pero no habían entrado en contacto hasta entonces; 3 ) los grupos que entran en contacto permanente, lo estuvieron en el pasado pero sólo de manera esporádica o casual; y 4) los grupos que entran en contacto permanente, lo estuvieron en el pasado pero dicho contacto se vio interrumpido bruscamente sin volverse a reanudar hasta entonces. De igual manera, cuando hablamos de grupos humanos en contacto, podemos identificar su relación sociocultural previa al contacto según dos modalidades: 1) los grupos en contacto pertenecen a una misma familia etnolingüística, y por lo tanto, o bien hablan lenguas emparentadas, o bien hablan dialectos de una misma lengua; y 2) los grupos en contacto no muestran ninguna relación etnolingüística aparente. Además, es posible imaginar un escenario donde los grupos en contacto son de distinto origen etnolingüístico pero comparten prácticas y sistemas de creencias similares, en parte como producto de una convivencia prolongada en un mismo entorno.

Al establecer una tipología de los grupos humanos en contacto, es preciso determinar la posición hegemónica o subalterna de los grupos, en cuyo caso se pueden identificar dos escenarios: 1) los grupos en contacto tienen ambos una posición hegemónica; 2) uno de los grupos en contacto tiene una posición hegemónica con relación al otro. La hegemonía y la subalternidad están asociadas directamente con el control de los recursos humanos, naturales y tecnológicos, el cual determina a su vez una posición favorable o desfavorable con respecto al otro grupo. La hegemonía no implica necesariamente dominio bélico sobre un grupo, aunque es común que se produzca junto con un control del territorio y los medios de producción. Hasta aquí esta breve tipología de situaciones y grupos en contacto.

\section{TRANSFORMACIONES DEL MITO EN SITUACIONES DE CONTACTO: SINTAXIS, ADAPTACIÓN Y FUNCIONALIDAD}

Como ya dijimos, el efecto del contacto de grupos humanos en la mito-poiesis y la mito-semiosis no pasó desapercibido para el mismo Lévi-Strauss, que dedica al tema dos de los artículos reunidos en su Antropología Estructural II (Lévi-Strauss 1987 [1973]). En su estudio sobre las «Relaciones de simetría entre ritos y mitos de pueblos vecinos», el etnólogo francés demuestra cómo los Mandan y los 
Hidatsa, dos grupos lingüísticamente emparentados (sioux), sin una visible relación jerárquica que pudiera haber desencadenado conflictos bélicos, crearon dos sistemas mítico-rituales perfectamente simétricos, es decir, sistemas que utilizan los mismos significantes y significados míticos (y rituales) pero cuya disposición (sintaxis) es la opuesta. En este caso, partiendo de un mismo grupo originario con una configuración mítica específica - es decir, con determinados significantes y significados míticos - se llega a una situación en la cual ambos grupos crean una composición diametralmente opuesta que hace uso de los mismos significantes y significados pero con sintaxis diferentes (simétricamente opuestas). Esto se representa visualmente en el siguiente esquema.

Tabla 1: Equivalencia sistemática especular de dos sistemas míticos en un mismo origen

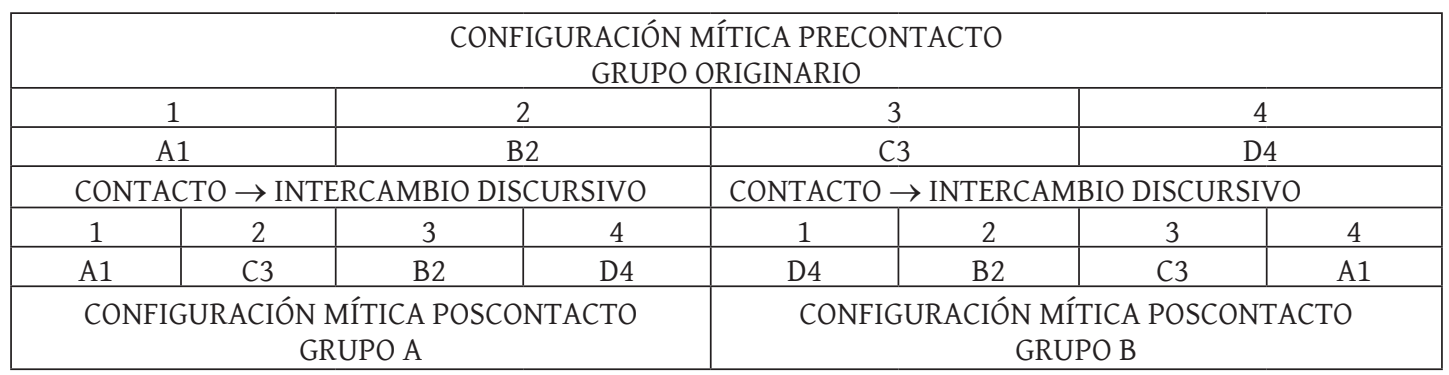

Como ilustra el esquema, se trata de los mismos mitos pero invertidos de tal manera que teniendo los mismos elementos, resultan imágenes especulares uno del otro. Detrás de semejante inversión sintáctica está, según Lévi-Strauss, un principio de individuación con fines identitarios:

«[L]a manera como los mitos fundadores de los rituales se oponen de una tribu a la otra como especies en el seno de un género, refleja la doble evidencia de un origen histórico distinto, para cada tribu afanosa de preservar su individualidad, y de una práctica que esta historia misma ha conducido a los dos pueblos a compartir [...] A fin de cuentas, si las costumbres de pueblos vecinos manifiestan relaciones de simetría, no hay que buscar la causa solamente en algunas leyes misteriosas de la naturaleza o del espíritu. Esta perfección geométrica resume también, en el modo presente, esfuerzos más o menos conscientes pero innumerables, acumulados por la historia y que apuntan todos a un mismo fin: alcanzar un umbral, sin duda el más provechoso a las sociedades humanas, donde se instaure un justo equilibrio entre su unidad y su diversidad» (Lévi-Strauss 1987: 241s)

Esta incorporación de los factores históricos dentro del análisis estructuralista resulta sorprendente desde todo punto de vista, pero no menos esperada, pues como el mismo análisis lo demuestra, incluirlos no sólo es la mejor sino la más fácil manera de explicar una configuración mítica tan dispar y similar a la vez. Consideramos que la "perfección geométrica» de los sistemas míticos resultantes del contacto fue posible en esta situación precisamente porque se trataba, según nuestra tipología, de dos grupos no sólo etnolingüísticamente similares sino además en igual posición política, de modo que uno no podía considerarse hegemónico o subalterno con respecto al otro. Sin embargo, el caso analizado es poco frecuente, pues la historia de la humanidad abunda en situaciones contrarias, esto es, aquellas en que grupos etnolingüísticamente distintos entran en una relación de fuerzas en la que uno ocupa una posición hegemónica. En estos casos, los resultados del contacto en la configuración mítica habrán de ser menos «simétricos» y hasta pueden resultar sincréticos o híbridos.

Entendemos por sincretismo mítico la combinación articulada de significantes y significados míticos de orígenes distintos, en la cual, pese a su origen dispar, prevalece la armonía en el sistema mitológico, pues se ha operado, como en el caso de los Mandan y los Hidatsa, una operación de reemplazo perfecta, mutatis mutandis, en virtud de la cual un significante o significado ha sido reemplazado en 
su misma posición sintáctica por otro funcionalmente equivalente. Por el contrario, la hibridez mítica implica una combinación de significantes y significados míticos de distintos orígenes, pero dicha combinación no sigue la sintaxis que tenían sus elementos antes de la mezcla sino otra diferente, en cuyo caso caben esperar resultados parcial o totalmente asimétricos; en este caso, las operaciones discursivas del mito se ven alteradas y hacen emerger nuevas combinaciones. Los esquemas 2 y 3 ilustran ambas combinaciones de significantes y significados como resultado de un contacto sociocultural asimétrico:

Tabla 2: Sincretismo mítico

\begin{tabular}{|c|c|c|c|c|c|c|c|}
\hline \multicolumn{4}{|c|}{$\begin{array}{l}\text { CONFIGURACIÓN MÍTICA PRECONTACTO } \\
\text { GRUPO A }\end{array}$} & \multicolumn{4}{|c|}{$\begin{array}{l}\text { CONFIGURACIÓN MÍTICA PRECONTACTO } \\
\text { GRUPO A }\end{array}$} \\
\hline 1 & 2 & 3 & 4 & 1 & 2 & 3 & 4 \\
\hline $\mathrm{A}_{1}$ & $\mathrm{~B}_{2}$ & $C_{3}$ & $\mathrm{D}_{4}$ & $\mathrm{~W}_{1}$ & $\mathrm{X}_{2}$ & $\mathrm{Y}_{3}$ & $\mathrm{Z}_{4}$ \\
\hline \multicolumn{4}{|c|}{ CONTACTO $\rightarrow$ INTERCAMBIO DISCURSIVO } & \multicolumn{4}{|c|}{ CONTACTO $\rightarrow$ INTERCAMBIO DISCURSIVO } \\
\hline 1 & 2 & 3 & 4 & 1 & 2 & 3 & 4 \\
\hline $\mathrm{W}_{1}$ & $\mathrm{~B} 2$ & $\mathrm{Y}_{3}$ & $\mathrm{D}_{4}$ & $\mathrm{~A}_{1}$ & $\mathrm{X}_{2}$ & $\mathrm{C}_{3}$ & $\mathrm{Z}_{4}$ \\
\hline \multicolumn{4}{|c|}{$\begin{array}{l}\text { CONFIGURACIÓN MÍTICA POSCONTACTO } \\
\text { GRUPO A }\end{array}$} & \multicolumn{4}{|c|}{$\begin{array}{l}\text { CONFIGURACIÓN MÍTICA POSCONTACTO } \\
\text { GRUPO B }\end{array}$} \\
\hline
\end{tabular}

Tabla 3: Hibridez mítica

\begin{tabular}{|c|c|c|c|c|c|c|c|}
\hline \multicolumn{4}{|c|}{$\begin{array}{c}\text { CONFIGURACIÓN MÍTICA PRECONTACTO } \\
\text { GRUPO A }\end{array}$} & \multicolumn{4}{|c|}{$\begin{array}{l}\text { CONFIGURACIÓN MÍTICA PRECONTACTO } \\
\text { GRUPO A }\end{array}$} \\
\hline 1 & 2 & 3 & 4 & 1 & 2 & 3 & 4 \\
\hline $\mathrm{A}_{1}$ & $\mathrm{~B} 2$ & $\mathrm{C}_{3}$ & $\mathrm{D}_{4}$ & $\mathrm{~W}_{1}$ & $\mathrm{X} 2$ & $Y_{3}$ & $\mathrm{Z}_{4}$ \\
\hline \multicolumn{4}{|c|}{ CONTACTO $\rightarrow$ INTERCAMBIO DISCURSIVO } & \multicolumn{4}{|c|}{ CONTACTO $\rightarrow$ INTERCAMBIO DISCURSIVO } \\
\hline 1 & 2 & 3 & 4 & 1 & 2 & 3 & 4 \\
\hline $\mathrm{B}_{2}$ & $\mathrm{~W}_{1}$ & $\mathrm{C}_{4}$ & $\mathrm{Y}_{3}$ & $\mathrm{Z}_{4}$ & $\mathrm{C}_{3}$ & $\mathrm{X}_{2}$ & $\mathrm{~A}$ \\
\hline \multicolumn{4}{|c|}{$\begin{array}{l}\text { CONFIGURACIÓN MÍTICA POSCONTACTO } \\
\text { GRUPO A }\end{array}$} & \multicolumn{4}{|c|}{$\begin{array}{l}\text { CONFIGURACIÓN MÍTICA POSCONTACTO } \\
\text { GRUPO B }\end{array}$} \\
\hline
\end{tabular}

Como se observa, ambas operaciones conllevan una mezcla de elementos, pero mientras en la primera se conserva la sintaxis mítica, en la segunda no ocurre lo mismo. Esto es, en la primera operación (sincretismo), el elemento mítico W1 del grupo B pasa a ocupar en la configuración mítica pos-contacto del grupo A, el mismo lugar que ocupaba el elemento A1 en la configuración mítica pre-contacto -esto es, el primer lugar de la secuencia. Por el contrario, en la segunda operación (hibridez), el elemento W1 pasa a ocupar en la configuración mítica pos-contacto del grupo A, un lugar diferente al del elemento B2 que reemplaza en la configuración mítica pre-contacto. En este caso no hablamos de una ausencia de sintaxis, sino de la creación de otra sintaxis mítica. Dicho de otro modo, a pesar de los cambios en la disposición de los elementos, la configuración mítica resultante tiene una sintaxis propia que difiere de las originarias. En este sentido disentimos de la afirmación hecha por Lévi-Strauss en cuanto que aquellos mitos que han pasado por transformaciones sucesivas -no necesariamente debidas al contacto- acaban por desarticularse y dejan de existir como tales (Lévi-Strauss 1987: 248). Lo que ocurre más bien es aquello que el mismo autor intuye líneas después: por un lado, la sustitución total de unos mitos por otros de origen diferente; por otro, el nacimiento de nuevos mitos. En ambos casos habrá de prevalecer la funcionalidad del mito para el grupo portador, requisito sine qua non de su transmisión.

El problema que representan para el análisis las mitologías sincréticas o híbridas radica en que, al ser tan profusa en ellas la mezcla de mitemas, no se puede establecer con exactitud el origen de ciertas configuraciones (elementos y sintaxis). Esto significa que si estudiamos la mitología de un 
grupo A, no podemos afirmar categóricamente en base a los resultados que dicha mitología contiene elementos originarios de B y/o C, pues ello depende solamente de la base de comparación, ya que si nuestro estudio se enfoca en la mitología del grupo B, igualmente podemos sostener que contiene elementos originarios de A y C. En pocas palabras, a nivel sincrético no es posible identificar el origen de los elementos, aunque sí su sintaxis; mientras que a nivel híbrido, ni el origen de los elementos ni el de su sintaxis son determinables en su origen. Este resultado resulta menos inesperado si se lo interpreta dentro de dos conceptos: el primero es el de área cultural, que se caracteriza precisamente por la difusión de elementos culturales que se recomponen formando un todo, y en el cual la asignación de origen a cada elemento es irrelevante; el segundo, más transparente todavía, es el de Sprachbund o área de convergencia lingüística, caracterizada precisamente por la presencia de un conjunto de lenguas de distintas familias, las cuales, en virtud de un contacto prolongado, han llegado a prestarse mutuamente elementos léxicos y gramaticales a tal punto que no sólo dan la apariencia de tener un mismo origen etnolingüístico -sin tenerlo- sino que es imposible determinar con certeza en qué lengua se originaron los elementos compartidos.

Todo lo dicho hasta aquí significa que el mito como forma discursiva tiende a conservarse en diferentes formas: 1 ) reproduciendo variantes de sí mismo dentro de subgrupos de un mismo grupo social; 2) construyéndose simétrica y especularmente a partir de otros mitos-modelo (el caso de los Mandan y los Hidatsa); 3) mezclando sus significantes y significados con los de otros mitos, unas veces conservando la sintaxis original, otras construyendo una nueva; y 4) siendo reemplazado en su integridad por otro mito -se asume- de función equivalente. La muerte de un mito no es posible dentro de esta tipología, pero no queda excluida en caso de que el mito en cuestión haya dejado de cumplir una función para el grupo portador, o bien en el caso extremo de que el grupo desaparezca bajo alguna forma de etnocidio perpetrada por un grupo más poderoso.

Al establecer una tipología de los posibles resultados del contacto en las configuraciones míticas, no podemos sino reconocer la enorme semejanza que guarda aquella con la tipología del cambio lingüístico, o más exactamente, con la vida y la muerte de las lenguas en situaciones normales y en situaciones de contacto. Así, el primer estadio del contacto, aquel que involucra subgrupos de un mismo grupo étnico que producen diferentes variantes míticas, corresponde a las variedades dialectales de una misma lengua; en este caso no hay mezcla de elementos míticos sino producción diferenciada. El segundo estadio, aquel que involucra el contacto de dos grupos etnolingüísticamente emparentados que construyen configuraciones míticas simétricamente opuestas, equivale al contacto de variedades de una misma familia lingüística que comparten un tronco común pero que normalmente no se hallan en posición jerárquica, como el caso de los grupos sioux (Mandan y Hidatsa); en este caso tampoco se da una mezcla pero sí un calco sintáctico inverso. El tercer estadio, que contempla el contacto de dos grupos etnolingüísticamente distintos y jerárquicamente relacionados que produce una configuración mítica mixta, conservando o recreando la sintaxis original de sus elementos, se asemeja en la lingüística de contacto a dos fenómenos: por un lado, al préstamo lingüístico, como el que existe entre el quechua y el castellano, donde la primera lengua toma prestado de la segunda elementos léxicos y gramaticales; y por otro, al fenómeno de las lenguas mixtas, que no son otra cosa que terceras lenguas formadas a partir de dos lenguas en contacto intenso y prolongado. El cuarto estadio, el reemplazo mítico, corresponde al proceso concluido de desplazamiento lingüístico de una lengua A hacia una lengua B. Finalmente, la muerte de un mito por disfuncionalidad equivale a dos escenarios: la muerte de una lengua que es abandonada en el plazo de una generación por las presiones sociolingüísticas violentas que ejerce el grupo dominante a favor de su propia lengua; y la muerte de una lengua cuando desaparece su último hablante o perece toda una comunidad de habla -caso menos extraño de lo que puede parecer si recordamos, por ejemplo, que los taínos de la Española, un grupo de filiación Caribe, sucumbieron en menos de tres décadas a la explotación y las epidemias. A propósito de estas últimas formas de contacto Amodio sostiene que el sincretismo mítico producto del contacto entre sociedades indíge- 
nas y grupos occidentales entraña la mayoría de las veces una dosis de violencia, la misma que está a menudo ausente en el contacto entre sociedades indígenas (Amodio 1989: 93).

Para entender cómo la dinámica del contacto influye en la mito-poiesis y la mito-semiosis, presentaremos un estudio de caso especial. Se trata de la mitología del pueblo alto-amazónico andoa, el cual, en virtud de los intensos y prolongados contactos interétnicos producidos a lo largo de su historia con grupos kichwas, jíbaros y zaparoanos, ha construido en su matriz mitológica todo un tejido innovador de elementos míticos de diferente cuño y origen.

\section{LOS ANDOAS: BREVE RELACIÓN HISTÓRICA Y ETNOLINGÜÍSTICA}

Los andoas en Ecuador tienen una población étnica de 1076 personas, repartidas en las comunidades de Puka Yaku, Jatun Yaku, Santa Rosa, Killu Alpa y Ashari. Ocupan en este país un territorio de aproximadamente 65.000 hectáreas en el sureste de la provincia de Pastaza. En el Perú, los andoas cuentan con una población aproximada de 2.300 personas, ubicadas en los asentamientos de Viejo Andoas, Kapawari y Nuevo Andoas, en las márgenes del Pastaza, en la provincia de Alto Amazonas del departamento de Loreto (ver Mapa 1). El territorio ancestral andoano se extendía ininterrumpidamente por la cuenca media y baja del Bobonaza en Ecuador, y por la cuenca media del Pastaza, en Perú.

Una de las características históricas del pueblo andoa es el hallarse rodeado de grupos de diferente origen étnico. Si tomamos, por ejemplo, la provincia ecuatoriana de Pastaza, veremos que hay en ella, a más de los andoas, seis nacionalidades diferentes: los záparos, los waorani, los kichwas, los shuar, los achuar y los shiwiar. Mientras záparos y andoas pertenecen a la misma familia lingüísti-

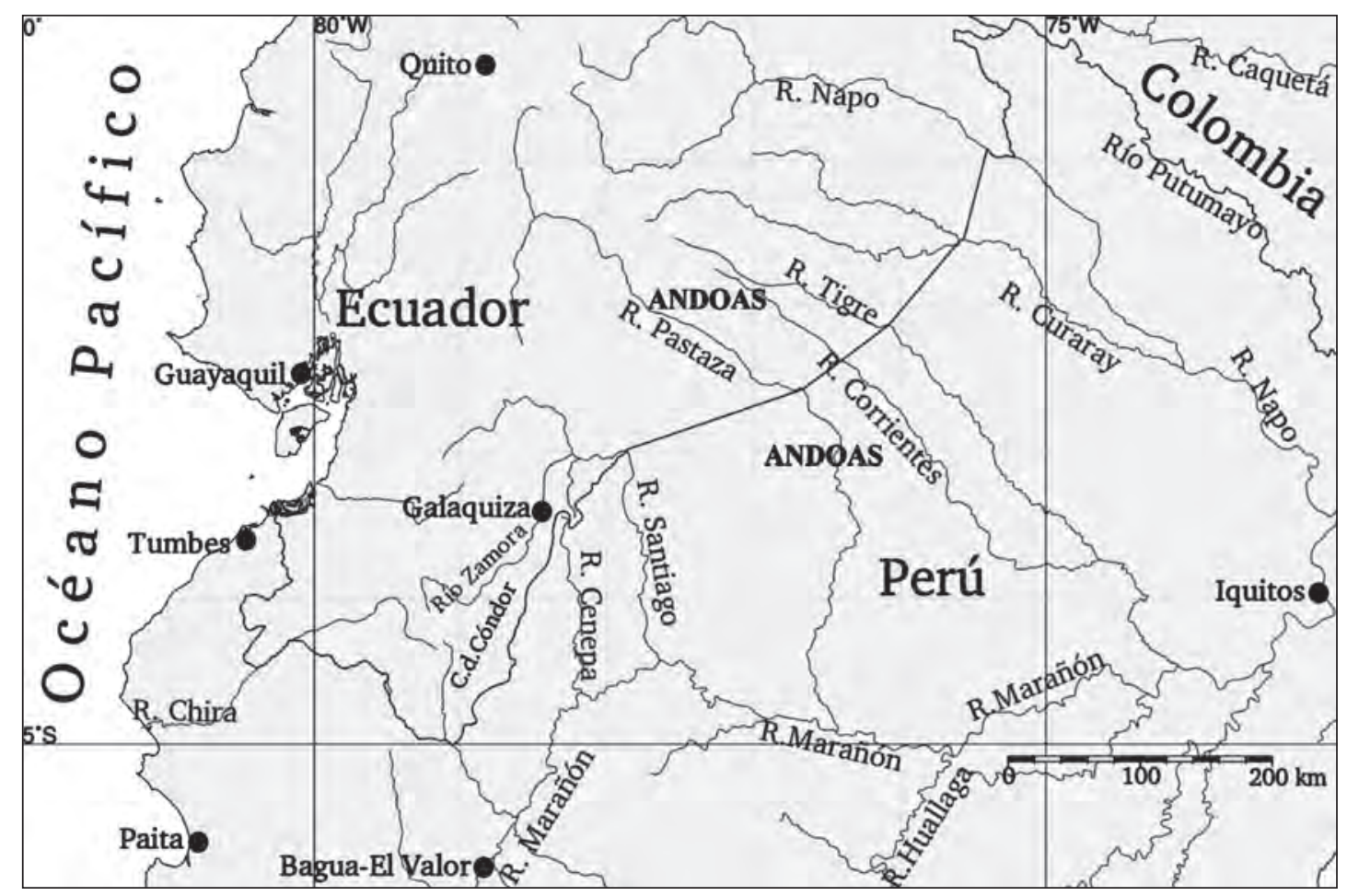

Mapa 1. 
ca (zaparoana), los grupos shuar, achuar y shiwiar se clasifican dentro del grupo lingüístico jíbaro³. Los kichwas y los waorani, por su parte, tienen una clasificación etnolingüística independiente: los primeros hablan una variedad del kichwa amazónico y pertenecen a la familia lingüística kichwa; los segundos hablan una lengua no clasificada hasta el momento. Con todos estos grupos étnicos los andoas han convivido a lo largo de su historia de diferentes maneras, pacífica y bélicamente, formando alianzas matrimoniales y librando conflictos interétnicos (Gómez Rendón 2011).

En el Perú, la convivencia multiétnica también es la regla. En efecto, los andoas peruanos mantienen relaciones con diferentes grupos: primero, con los kichwas, de quienes han asimilado su lengua y su cultura en un proceso de kichwización que prácticamente ha concluido; con los shuar y los achuar, con quienes por lo general han mantenido una relación conflictiva; y con los muratos o shapras, de filiación etnolingüística desconocida (lengua candoshi), pero muy cercanos a los grupos jíbaros. Por otro lado, aunque separados por varios centenares de kilómetros, viven en el departamento de Loreto dos grupos de filiación zaparoana, los arabelas y los iquitos, etnolingüísticamente emparentados con los andoas.

El etnónimo 'andoa' muy probablemente se origina del término 'kanduash', proveniente a su vez del etnónimo 'kandoshi', que no es otro que el de los propios muratos. Esto no significa que muratos y andoas tengan un mismo origen etnolingüístico. El haber adoptado a lo largo de los años un etnónimo de distinto origen étnico se debe a que los andoas estuvieron agrupados desde 1708 en la Misión de Santo Tomás de Andoas, heredera de otra en torno a la cual se agruparon mayormente grupos muratos o 'kanduas', de los cuales tomó el nombre la misión (Gómez Rendón 2011: 22). Un reciente trabajo de documentación de la hoy extinta lengua andoa con sus últimos hablantes en el Perú y la compilación lexicográfica resultante nos permitieron demostrar que la lengua andoa (también llamada shimigae) es indudablemente de origen zaparoano, y se ha de clasificar, por lo tanto, dentro de la misma familia que el zápara, el arabela y el iquito. Las cuatro lenguas provienen de un tronco común llamado proto-zaparoano. De acuerdo con estudios glotocronológicos (Payne 1984, Stark 1985), los hablantes del protozaparoano, una vez llegados en sucesivos desplazamientos hasta las cabeceras del Tigre, habrían formado la rama arabela-andoa, de cuya segunda extensión, la andoa, se habría escindido luego el grupo de hablantes del zápara, divididos en los grupos Bobonaza-Conambo y Curaray.

\section{RELACIONES INTERÉTNICAS ENTRE ANDOAS Y ZÁPAROS}

Dada su cercanía lingüística y cultural, las primeras y quizás más importantes relaciones interétnicas establecidas históricamente por los andoas involucran a otros grupos zaparoanos, en particular al grupo zápara del Ecuador ${ }^{4}$. En primer lugar, andoas y záparos compartieron el espacio de las misiones, lugar privilegiado de relaciones interétnicas. En segundo lugar, fue costumbre entre ambos grupos no sólo mantener alianzas matrimoniales y redes de parentesco sino también formar alianzas de guerra contra grupos jíbaros que penetraban en su territorio. En tercer lugar, sus costumbres, como es lógico, tenían mucho en común, desde el vestido hasta la gastronomía. Aunque en la actualidad no existen relaciones

3 No está por demás recalcar que nuestro uso del término 'jíbaro' nada tiene de peyorativo y sólo sigue el uso dado en la clasificación lingüística corriente (véase, por ejemplo, Lewis 2009). En reemplazo de este exónimo se han propuesto al menos dos etnónimos propios, como son aents y chicham, cuyo uso empero no ha ganado aceptación todavía en los círculos científicos.

4 Llama la atención que en la narrativa andoana recogida en Perú sean escasísimas las referencias a los záparos, lo cual podría explicarse, a mi entender, por dos circunstancias: que la separación geográfica entre las comunidades andoas y las comunidades záparas es más grande en el Perú que en Ecuador, donde sus territorios colindan en buena medida; y que los záparas en Perú tenían hasta hace poco una organización política débil y eran conocidos como parte de los kichwas amazónicos, cuya lengua hablan hoy en día todos sus miembros sin excepción. 
tan estrechas como en el pasado, ambos grupos se reconocen hermanos y subsisten relaciones de parentesco entre familias. Existen en Ecuador y Perú varios casos de záparas residentes en territorio andoano, donde han sido recibidos e incorporados a la comunidad sin obstáculo alguno.

\section{RELACIONES INTERÉTNICAS ENTRE ANDOAS Y KICHWAS}

Otro grupo con el cual los andoas mantuvieron históricamente buenas y estrechas relaciones, y del cual acabaron adoptando su lengua y otros rasgos culturales, son los kichwas de Pastaza, conocidos como Canelos en el Ecuador (Whitten 1976). Pese a que no comparten el mismo origen lingüístico, los dos grupos entraron en contacto desde muy temprano y formaron alianzas de guerra y parentesco. En el pasado, alrededor de la misión de Canelos, creada en el siglo XVII, se congregaron los gaes, un pueblo zaparoano directamente emparentado con los shimigaes o andoas. En la actualidad, los andoas de las comunidades del bajo Bobonaza e incluso del medio Pastaza peruano tienen familiares cercanos y lejanos en prácticamente todas las comunidades kichwas del curso superior del Bobonaza. Esto se debe a que -al menos antes de 1941- existió un contacto permanente entre los andoas y los canelos kichwas de Pastaza, como resultado de lo cual se crearon redes de parentesco y un asentamiento de andoas originarios a lo largo del curso superior del Bobonaza. Resulta interesante la causa de la movilidad y el contacto: el comercio de la sal. En efecto, la sal fue uno de los artículos de comercio más importantes a nivel interétnico por su valor práctico y simbólico. En lo práctico, servía para conservar la carne y el pescado. En lo simbólico, tenía un valor de cambio, a manera de moneda, y se utilizaba como obsequio entre familiares, compadres y amigos.

En Ecuador, hasta la creación de sus respectivas organizaciones, andoas y záparos eran considerados parte del pueblo kichwa amazónico y no se distinguían de otros pueblos kichwas de selva. Esto no significa que se considerasen iguales. Al contrario, la construcción identitaria andoana apunta a una visibilización a través de su reconocimiento como colectivo histórico con derechos y obligaciones en el marco de un estado plurinacional que trasciende incluso las fronteras nacionales.

\section{RELACIONES INTERÉTNICAS ENTRE ANDOAS, JÍBAROS Y MURATOS}

La relación que mantienen los andoas con los grupos jíbaros y la que se opera a nivel de la memoria social con los históricos muratos se orienta a profundizar las diferencias con ambos grupos. Estas diferencias presuponen a la vez similitudes con otros grupos -záparos y kichwas- con quienes guardan relaciones de parentesco y amistad, que en el pasado les unían en la guerra contra jíbaros (shuar, achuar, shiwiar) y muratos (candoshi). Es importante señalar que después de 1941 los muratos se quedaron todos en territorio peruano y por lo tanto fuera de todo contacto con los andoas del Ecuador; no así con los del Perú, con quienes todavía mantienen ciertas relaciones al encontrase algunas de sus comunidades en las cercanías de Viejo Andoas a orillas del Pastaza. Es interesante que los muratos todavía sigan presentes en la tradición oral andoa, que guarda historias de sus incursiones contra poblaciones andoanas.

Mientras la mayoría de ataques muratos se producían alrededor de la antigua misión de Santo Tomás de Andoas y tenían como fin el robo de sal y otras mercancías, los ataques a lo largo del río Bobonaza, es decir, alrededor del centro misionero de Juanjiris (curso inferior del Bobonaza) y de las poblaciones kichwas de Canelos (curso superior), Pakayaku y Sarayaku (curso medio), involucraban a grupos jíbaros que practicaban el rapto de mujeres. En general, los testimonios recogidos en las comunidades andoanas del Ecuador demuestran que los conflictos con grupos jíbaros por mujeres y mercancías fueron numerosos en toda la cuenca del Bobonaza; también nos enseñan que dichos conflictos fueron enfrentados a través de alianzas, basadas no sólo en rasgos culturales y lingüísticos compartidos sino también en relaciones de parentesco entre zaparoanos (andoas, záparas) y no-zaparoanos (canelos kichwas). Aun así, a inicios de los años veinte no era inusual que individuos de habla shuar o achuar convivieran con andoas en la misión dominica de Juanjiris (actual Montalvo), a donde venían a refugiarse de las guerras 
intertribales con otros grupos jíbaros ubicados al sur ${ }^{5}$. Es decir, en Juanjiris ocurría lo mismo que en la misión de Santo Tomás de Andoas: la presencia permanente de un grupo de hablantes no zaparoanos, shuar o achuar en la primera misión, muratos en la segunda ${ }^{6}$.

Ningún informe misionero ofrece información exacta sobre el número de los llamados jíbaros en la misión de Juanjiris. Tampoco dice si se trataba de shuaras o achuaras -aunque por su origen, los bautizados parecen haber pertenecido al segundo grupo. En todo caso, son varias las referencias a los jíbaros de Juanjiris, lo cual sugiere que su número no era despreciable. Es posible incluso que el número de habitantes de origen jíbaro y el de sus descendientes fuera lo suficientemente importante como para formar dos mitades ${ }^{7}$. Esta conformación se encontraba en numerosos asentamientos misionales de composición interétnica. En el caso de Santo Tomás de Andoas las dos mitades estaban formadas por andoas y muratos (Spruce 1908: 112). En el caso de Juanjiris las mitades estuvieron formadas por andoas y jíbaros, como lo pudo comprobar un dominico que visitó el nuevo asentamiento de Montalvo (antiguo Juanjiris) en 1942 (Bernardo Espinosa 1942: 349).

Por todo lo anterior, está claro que hablantes de habla jíbara estaban presentes en todas las misiones dominicas a principios del siglo xx, incluidas aquellas a orillas del Bobonaza (Canelos, Pakayaku, Sarayaku, Juanjiris, Santa Rosa del Bufeo), del Pastaza (Andoas), y de otros ríos (Santa Teresita del Villano y Santa Rosa del Conambo). Además, no olvidemos que después de su fundación en el siglo XVII, Canelos recibió achuaras que se refugiaban en la misión para protegerse de las guerras intertribales. Lo mismo sucedió en los siglos XVIII y XIX en Pakayaku y Sarayaku, caseríos anejos de Canelos que nacieron y crecieron con presencia de gente achuar y en los cuales se avecindaban en ocasiones individuos de las jibarías del Copataza. Debido a la guerra intertribal entre las parcialidades jíbaras, la suerte que corrían en numerosas ocasiones las misiones al albergar a gente de las jibarías fue la de verse involucradas en la guerra o incluso terminar destruidas ${ }^{8}$.

\section{RELACIONES INTERÉTNICAS ANDOAS Y WAORANIS}

No se registran en la tradición oral andoana referencias explícitas sobre conflictos con el grupo waorani, aunque sí existen referencias a encuentros ocasionales. Más frecuentes son en la tradición oral zápara, pues fueron éstos quienes mantuvieron, en razón de su ubicación, un conflicto permanente con los waorani hasta finales del siglo XIX. De cualquier manera, no se puede excluir enfrentamientos, así fueran esporádicos, entre waoranis y andoas, sobre todo con los andoas asentados en la cuenca del Bobonaza (actual Ecuador), por hallarse más cerca del territorio tradicional waorani que los andoas del curso medio del Pastaza en el Perú. Es posible incluso que los encuentros entre ambos grupos se intensificaran desde finales del siglo XIX, cuando el territorio de la cuenca del Curaray, de ocupación tradicional zápara, quedó ampliamente despoblado por el reclutamiento forzado de sus habitantes para la explotación del caucho y ocupado subsiguientemente por grupos waoranis (Cabodevilla 1999: 269s). Sin embargo, a diferencia de los conflictos permanentes mantenidos con grupos jíbaros y mu-

5 Al respecto véase, R. P. Ceslao de Marín. «Informe de la segunda visita a los pueblos de Sarayacu y Juanjiris», Oriente Dominicano, 20 de agosto de 1929.

6 Reeve incluso sostiene que los muratos lograron subir hasta Sarayacu y establecieron alianzas con sus habitantes, dedicándose además al comercio de la sal y el curare (Reeve 1998: 102).

7 Las relaciones entre mitades no siempre fueron pacíficas. Para el caso de la misión de Andoas, por ejemplo, sabemos que en 1897 se fundó cerca de la desembocadura del Bobonaza un pequeño pueblo llamado «La Unión», que albergaba a los indios del partido alto que estaban en conflicto con los del partido bajo.

8 En 1887, por mencionar un caso, la misión de Pacayacu fue destruida por completo por guerreros de la jibaría del Copataza (Humberto Mejía, «Rasgos históricos acerca del pueblo de Pacayacu», Oriente Dominicano, Año 2, 1927, p. 32). Para una historia similar en el caso de Canelos, véase Simón Hurtado, «Apuntes para la historia», Oriente Dominicano, 1939, pg. 47. 
ratos, con quienes además compartían el espacio de las misiones, los andoas nunca vivieron un estado de guerra continua con los waorani ni mucho menos convivieron con ellos en forma alguna, por lo que podemos clasificar la relación entre ambos grupos como poco menos que casual y por tanto de ninguna influencia en las prácticas culturales y los sistemas míticos de ambos pueblos.

Hasta aquí el trazado de las relaciones interétnicas de los andoas con otros grupos del espacio alto-amazónico. Como es obvio, a más de las relaciones arriba esbozadas, existen aquellas con la población blanco-mestiza, desde el nacimiento de las misiones hasta el presente. Estas relaciones han sido tratadas en otro lugar (Gómez Rendón 2011) y no las mencionamos aquí por ser nuestro objetivo identificar en el corpus mítico aquellos elementos que los andoas comparten con otros grupos indígenas, precisamente aquellos con quienes han estado en contacto. Antes de proceder al estudio del corpus en busca de dichos elementos, es preciso que describamos brevemente el proceso de su recolección y análisis, así como el corpus mítico pluriétnico comparativo.

\section{El CORPUS MÍTICO}

La presente investigación parte de una base empírica constituida por un corpus mítico que el autor recogiera en las poblaciones andoanas del Perú con ocasión de la documentación que se llevó a cabo en 2009 y 2010 para la recuperación de la historia y la lengua andoa. Aunque se recogieron un total de diecinueve mitos, dado el alcance del presente trabajo, hicimos una selección de las narraciones a fin de conformar un corpus de trabajo de cinco relatos. Esta selección, sin embargo, estuvo determinada no sólo por su lugar central en el cuerpo mitológico sino también por la existencia de compilaciones similares para otros grupos alto-amazónicos.

Todos los relatos fueron recogidos en kichwa, con algunas secciones en lengua andoa -generalmente paráfrasis de oraciones kichwas. La transcripción y traducción al castellano de los relatos fue realizada por Gabriel Santamaría, profesor y líder de la comunidad andoa de Jatunyaku, que trabajó además como asistente lingüístico local y continúa a la fecha como promotor cultural en el Ecuador. Las tareas de transcripción y traducción fueron facilitadas por el uso de un software de anotación interlineal con audio y video sincronizado (ELAN). La traducción castellana fue editada por el autor, procurando mantener en lo posible el espíritu de la narrativa y estandarizando la escritura. La siguiente es la lista de los mitos escogidos:

Tabla 4. Mitos andoas del corpus referencial

\begin{tabular}{|c|c|c|}
\hline Amasanga Unanchay & $\rightarrow$ & Mito de Amasanga \\
\hline Inti Unanchay & $\rightarrow$ & Mito del Sol \\
\hline Killa Unanchay & $\rightarrow$ & Mito de la Luna \\
\hline Tukiraja Warmi Unanchay & $\rightarrow$ & Mito de Tukiraja \\
\hline Wito-Achiote Unanchay & $\rightarrow$ & Mito de Wito y Achiote \\
\hline
\end{tabular}

Para el análisis de los mitos se procedió a identificar sus unidades constitutivas o mitemas, que luego de una lectura atenta de cada pieza se formularon a manera de enunciados, es decir, como oraciones con sujeto y predicado. Como no es nuestra tarea comparar variantes de un mismo mito dentro de la mitología de un pueblo, sino más bien comparar mitos equivalentes entre las mitologías de varios pueblos, no numeramos los mitemas. Más importante fue realizar, previo al análisis mitémico, una identificación de temas, personajes y lugares a fin de tener una base de comparación con mitologías de otros pueblos amazónicos. 
El primer elemento de la comparación estuvo dado por el corpus mítico andoano. El segundo elemento, algo más complejo, se compuso de un conjunto de mitos de grupos étnicos de contacto, como vimos en la sección precedente. Este corpus pluriétnico incluyó, por lo tanto, piezas de la tradición oral de los siguientes pueblos amazónicos: kichwas de Pastaza (Ecuador-Perú); kichwas de Napo (Ecuador); záparos (Ecuador-Perú); shuar y achuar (Ecuador-Perú); y muratos (Perú). Adicionalmente, se tomó como referencia las mitologías arabela (Perú) e iquito (Perú), de grupos zaparoanos geográficamente lejanos pero etnolingüísticamente emparentados con los andoas.

La conformación del corpus pluri-étnico no estuvo exenta de dificultades, sobre todo por la desigual provisión de materiales para los diferentes grupos. Así, por ejemplo, mientras existe copioso material mitológico para los grupos kichwas de Napo y Pastaza, como también para los grupos jíbaros de ambos lados de la frontera, las fuentes que recogen mitos záparas son muy reducidas, más todavía las recopilaciones de mitos muratos, arabelas e iquitos. Esta desigual disponibilidad de fuentes limitó nuestra pesquisa en la medida que los temas, personajes y lugares que sirvieron de referencia para la selección de mitos a comparar fueron solamente de los mitos disponibles. En conjunto, el corpus pluri-étnico comprende un total de veintisiete (27) relatos, todos en castellano -aunque en algunos casos contienen una versión original en la lengua indígena. Las fuentes utilizadas se encuentran detalladas en la bibliografía.

Al igual que el corpus mítico andoa, el corpus pluriétnico fue analizado siguiendo el mismo procedimiento, es decir, identificando sus unidades constitutivas mayores (mitemas), formulándolas a manera de enunciados constituidos por sujeto y predicado, y ordenándolas en secuencia pero sin numeración.

La Tabla 1 contiene, en la primera columna, el nombre de los mitos que conforman el corpus andoa. Las siete columnas siguientes corresponden respectivamente a cada uno de los grupos étnicos cuya mitología hemos analizado. Los números entre paréntesis indican la paginación que les corresponde en la fuente respectiva citada en la bibliografía.

\section{ANÁlisiS MITOLÓGICO COMPARATIVO: LA MITOLOGÍA ANDOA EN EL ÁREA ALTO-AMAZÓNICA OCCIDENTAL}

Al hablar de zonas de contacto en la primera sección, caracterizamos el área del alto Amazonas occidental como escenario cultural donde han tenido lugar una serie de migraciones, confluencias e intercambios entre los diferentes grupos étnicos que pueblan o han poblado la región. A su vez, dentro de esta área, identificamos otra más circunscrita, llamada 'montaña' por Steward y Metraux (1948). Mientras los siete grupos étnicos con quienes han entrado en contacto los andoas encajan geográficamente en el área cultural del alto Amazonas occidental, su pertenencia a la subárea cultural de 'montaña' no queda clara, sobre todo porque la definición misma de 'montaña' resulta ambigua en términos geográficos, bien por la alusión que conlleva en castellano, bien porque en ella se clasifican tanto grupos étnicos de la llanura amazónica o selva baja como grupos de la zona subandina o piedemonte oriental. Así, por el oriente, el grupo más extremeño son los iquitos, cuyo hábitat se encuentra en la selva baja, a menos de 300 msnm; más al oeste, todavía por debajo de los 300 msnm, están los arabelas, grupo zaparoano como los iquitos. Por el occidente, los kichwas canelos se encuentran en la zona subandina del Ecuador, entre 300 y 700 msnm. Las tres comunidades andoanas del Perú (Viejo Andoas, Kapawari y Nuevo Andoas), por su parte, se hallan en la llanura amazónica, con altitudes que oscilan entre 200 y $215 \mathrm{msnm}$, mientras las comunidades andoanas del Ecuador superan con poco el umbral de la selva baja y se hallan por tanto dentro del piedemonte, con alturas que varían entre 305 y 320 msnm.

Valga esta digresión para señalar que si bien existen diferencias geográficas en el hábitat de los siete grupos étnicos considerados, es posible encontrar en todos una comunión de rasgos culturales, muchos de ellos condicionados ambientalmente, que nos permiten clasificarlos como parte de una misma área cultural. No obstante, es preciso recalcar que esta comunión de rasgos no implica en ningún caso 


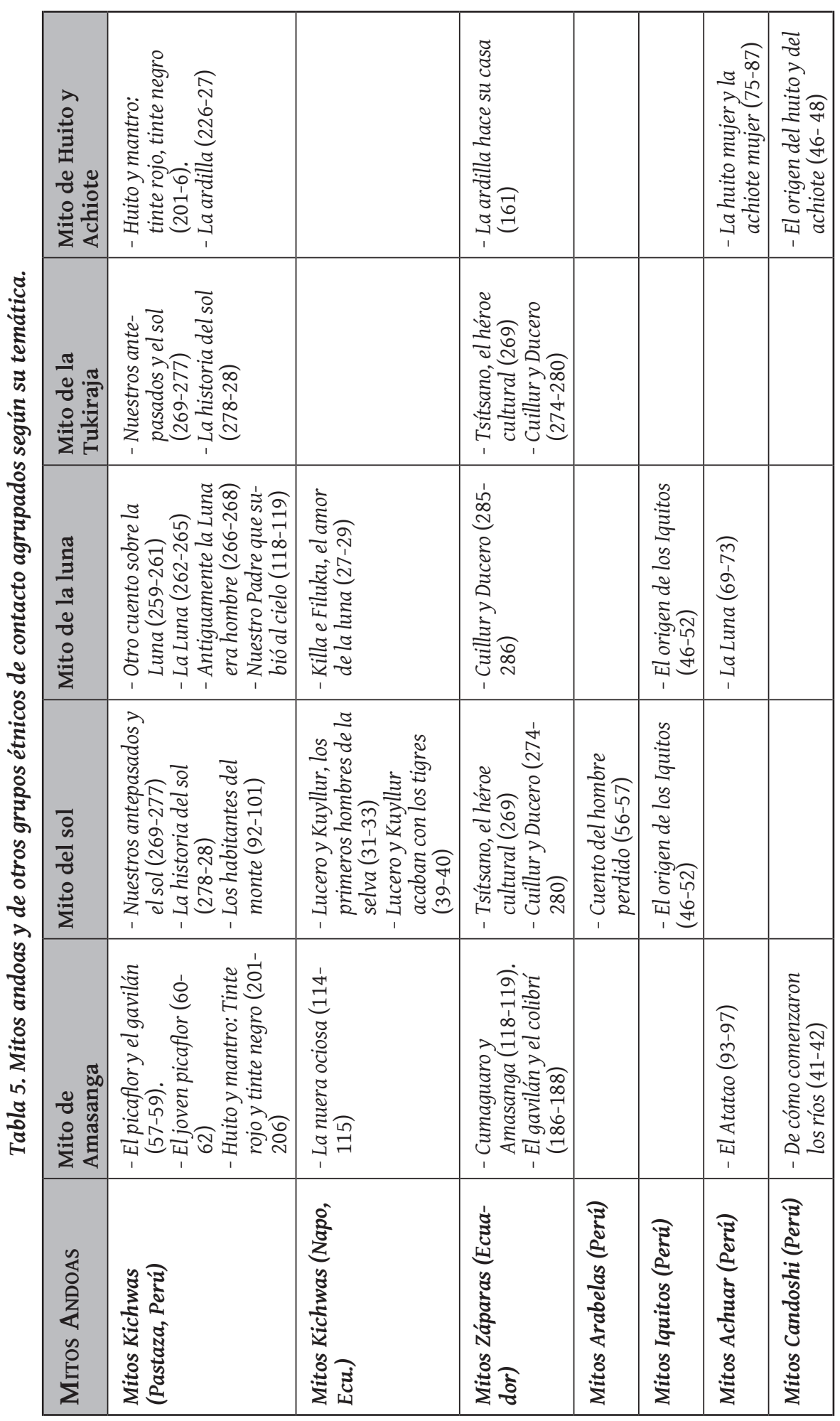


uniformidad: ni lingüística, por el gran número de lenguas de distinta filiación que se encuentran en el área; ni cultural, porque el área receptó durante siglos migraciones de pueblos amazónicos orientales $\mathrm{y}$ andinos que hallaron en ella una zona de refugio desde mediados del siglo XVI, y desde entonces, en virtud del contacto, dieron paso a complejos procesos de etnogénesis que continúan hasta hoy (Whitten 1976; Naranjo 1977). Si añadimos a lo anterior la influencia de las misiones, podemos imaginarnos cuán numerosos han sido los intercambios en la tradición oral de los pueblos alto-amazónicos. En consecuencia, por encontrarse los andoas a medio camino entre los extremos del área geográfica y cultural del alto Amazonas y por los antecedentes históricos discutidos en $\S 2$, podemos esperar que la suya sea una tradición oral que recoja elementos de la mayoría de grupos étnicos regionales.

\section{INSTRUMENTACIÓN DEL ANÁLISIS MÍTICO COMPARATIVO}

Si queremos demostrar la interrelación a nivel de los mitos de los grupos étnicos estudiados, es preciso demostrar primero que dichos mitos tienen temas, personajes y lugares compartidos. En tal medida, el procedimiento heurístico a seguir consistirá en identificar en el corpus andoa los temas, personajes y lugares más importantes, para luego buscarlos en el corpus mítico pluriétnico que servirá de comparación. No obstante, el análisis se queda corto si nos remitimos a hallar semejanzas. Es preciso saber cómo, cada mitología, ha tejido temas, personajes y lugares siguiendo una sintaxis particular. Para ello es preciso entender los temas, los lugares y los personajes como unidades sígnicas compuestas de un significante (expresión en la lengua respectiva, o traducción de dicha expresión a otra lengua) y un significado (concepto generalmente asociado a dicho significante en la cultura y la mitología del grupo). La composición de unidades sígnicas forma un enunciado o mitema. En términos lingüísticos, cada tipo de unidad sígnica corresponde a un sintagma a nivel del significante (los personajes son sintagmas nominales; los temas, sintagmas verbales; los lugares, sintagmas adverbiales o preposicionales) y a una función gramatical (los personajes son sujetos; los temas, predicados; los lugares, complementos) a nivel del significado.

De acuerdo con este modelo, cuando dos cosmovisiones entran en contacto a través de sus respectivas mitologías, pueden tomar prestadas no sólo unidades sígnicas sino también mitemas (enunciados compuestos de unidades sígnicas); también puede darse el caso de que el préstamo sea, en el caso de las unidades sígnicas, solo de significantes o sólo de significados; y en el caso de los enunciados o mitemas, que se tome prestada una sintaxis (orden de unidades sígnicas u orden de enunciados) o que se presten proposiciones específicas (predicaciones hechas con respecto a un sujeto). Los resultados son, por lo tanto, diversos. La siguiente es una tipología que abarca las distintas formas que puede tomar el intercambio de material y sintaxis míticos:

a. Un mitema, uno de cuyos elementos es un significante prestado;

b. Un mitema, uno de cuyos elementos es un significado prestado;

c. Un mitema, dos de cuyos elementos son significantes prestados;

d. Un mitema, dos de cuyos elementos son significados prestados;

e. Un mitema cuyos elementos son todos significantes prestados;

f. Un mitema cuyos elementos son todos significados prestados;

g. Un mitema con sintaxis prestada, proposición original ${ }^{10}$ y significantes prestados ${ }^{11}$;

9 Es un caso extremo de traducción mitológica.

10 Por 'proposición original' entendemos el contenido de un enunciado en la matriz mitológica donde ha sido creado.'Proposición diferente’ será, pues, el contenido de un enunciado que no corresponde a la matriz receptora.

11 Es imposible un mitema con sintaxis prestada o propia, que conserve la proposición pero no los significados. 
h. Un mitema con sintaxis propia, proposición diferente y significantes propios;

i. Un mitema con sintaxis prestada, proposición diferente y significantes propios;

j. Un mitema con sintaxis prestada, proposición diferente, significantes prestados ${ }^{12}$.

En la siguiente sección nos ocupamos de identificar las unidades sígnicas de los mitos andoas (personajes-sujetos, temas-predicados, lugares-complementos) para luego correlacionarlas con sus equivalentes en los mitos de los siete grupos étnicos estudiados. Luego viene una sección donde estudiamos en qué manera se combinan las unidades sígnicas en mitemas tanto en el corpus andoa como en el corpus pluri-étnico, a fin de identificar las formas de mezcla de significantes, significados, sintaxis y proposiciones según las combinaciones posibles.

\section{PERSONAJES (SUJETOS) EN LOS MITOS ANDOAS}

A partir del análisis del corpus mítico andoa, contabilizamos un total de cincuenta y dos personajes. Nótese que a nivel de la unidad sígnica, el personaje corresponde al significante y sus características al significado. Los personajes se clasifican en dos grandes grupos potencialmente intercambiables (zoomorfos y antropomorfos). En el grupo de personajes zoomorfos identificamos, en primer lugar, las distintas especies de aves, entre las cuales se destacan, de las más a las menos frecuentes, el paujil (familia Cracinae), el papagayo, la lechuza, la garza, el trompetero (familia Fringillidae), el paucar (Cacicus cela), el murciélago, el chikuan (familia Cuculidae) y la tijereta (familia Tyranidae). De los mamíferos encontramos, también en orden de frecuencia, el tigre (macho o hembra, viejo o joven), la ardilla y el mono machín. Dos subgrupos poco representados son los insectos (hormigas y abejas) y los peces (pirañas y bocachicos).

El grupo de caracteres antropomorfos comprende la pareja de mujeres jóvenes (con o sin relación de parentesco); la pareja de hombres jóvenes (con o sin relación de parentesco). Tomados individualmente, los caracteres antropomorfos son los siguientes: la mujer, que cumple los roles de novia, esposa, madre, que puede ser joven o anciana, y que trabaja como cocinera o alfarera; el hombre, que hace las veces de novio, esposo, padre, que puede ser joven, viejo o incluso ser un muerto viviente, y que trabaja como agricultor, cazador o pescador; y por último, el infante, siempre varón, que eventualmente crece y se hace joven. Adicionalmente hay personajes astrales, como el sol y la luna, en cuanto producto de una transformación que funda el orden cosmológico; pero también, por sus rasgos vitales, personajes vegetales, como los árboles de wito (Genipa americana) y achiote (Bixa Orellana) y palmeras como la chonta, o incluso enredaderas o bejucos trepadores.

Cada personaje tiene asignado un significado primario según las características explícitas en la narrativa o implícitas en la cultura. Así, el tigre, en cualquiera de sus formas, es siempre cazador asesino y/o glotón, mientras el paujil aparece sin excepción como revelador de información y fuente de ayuda. Las mismas características, en virtud de la tenue línea que separa los personajes zoomorfos de los antropomorfos en el mito, se hallan presentes en hombres y mujeres e incluso en los personajes astrales. Así, el joven Sol es cazador como los tigres; la mujer Tukiraja ${ }^{13}$ es cocinera como la vieja tigresa; la mujer del mito de Tukiraja está embarazada, al igual que la tigresa que se salva de las pirañas; Amasanga es buen trabajador, como es el paucar. Es decir, existen características que son compartidas por los personajes, aunque no todas se repitan en un mismo personaje, de suerte que es posible realizar un análisis componencial del significado de los personajes para clasificarlos en categorías comunes. Por ejemplo, son cazadores el Sol, los tigres y Amasanga; son informantes el paujil, el papagayo, el tucán y el chikuan; son madres la tigresa joven, la tigresa vieja y la Tukiraja; son hermanas las trompeteras, la mujer wito, la mujer achiote, y las mujeres que rechazan a Amasanga, etc.

12 Otro caso extremo, que llamaremos mito-génesis, donde desaparece un mitema para engendrar otro.

13 Todo parece indicar que el término 'tukiraja', de origen zaparoano, está asociado con la luna y lo amarillo (como killa en kichwa) y se utiliza sobre todo con relación a la chonta. 
No es posible, dada la extensión de este trabajo, realizar un análisis componencial exhaustivo en los términos arriba señalados. Baste aquí señalar su heurística y su necesidad para una comprensión cabal de los mitos, sobre todo porque estas características tienen una asociación cultural más profunda a nivel de la cosmovisión, y porque según el grupo de que se trate, es posible asignar uno o más significados (características) a un significante (personaje).

\section{TEMAS (PREDICADOS) EN LOS MITOS ANDOAS}

Tomadas en conjunto, las unidades sígnicas que funcionan a nivel del mitema como predicados son las más numerosas (187 predicados). Por su naturaleza predicativa, estas unidades otorgan características a otras y son, por tanto, de carácter relacional. Su significante siempre es un verbo (simple o compuesto) o una cópula. Su significado está dado por la suma de los roles semánticos, es decir, del número de participantes del estado o acción al que se refiere el verbo. Así, por ejemplo, el tema 'matar' está definido por un predicado donde hay al menos dos participantes, un agente (asesinocazador) y un paciente (asesinado-cazado), pudiendo añadirse optativamente un instrumento (la flecha, la lanza, etc.) o un lugar (la selva, la casa, etc.). El análisis nos permitió identificar cuáles son los predicados más comunes y su estructura de participantes, es decir, qué personajes están asociados con qué acciones.

Proponemos una clasificación general de los predicados en base a su transitividad o intransitividad, es decir, según si el verbo rige uno o más objetos (transitivo), o ninguno (intransitivo). En el primer caso, se pueden identificar predicados mono-transitivos (un objeto) y predicados ditransitivos (dos objetos). Predicados mono-transitivos comunes se expresan, por ejemplo, a través de los verbos 'cazar' y 'matar', que comparten también un mismo campo semántico, con la sola diferencia de que el primero se refiere a seres zoomorfos y el segundo a seres antropomorfos. En este caso es común que las características de cazador y asesino ('que quita la vida') se conjuguen en un mismo personaje (el joven Sol, por ejemplo). En la misma categoría están los verbos 'comer' y ‘beber', cuyos objetos más comunes son la carne de cacería y la chicha o el masato, respectivamente. Por lo demás, es interesante que los predicados 'comer' y 'defecar' entren en oposición explícita fundante del carácter de dos personajes míticos, Tukiraja y las hormigas (seres sin ano): en efecto, Tukiraja come comida y defeca heces mientras las hormigas comen heces y defecan comida. Otro predicado mono-transitivo de uso corriente es 'oler a alguien', que agrupa a dos actantes, los tigres como sujetos y un ser humano como objeto.

No deja de ser interesante que algunos verbos mono-transitivos estén asociados con predicados ditransitivos, como por ejemplo 'comer' con 'dar de comer', o 'beber' con 'dar de beber'. En este caso la narrativa involucra casi siempre a dos personajes antitéticos: un ejemplo es el joven Sol que 'da de comer' a los tigres, cuando por su condición de humano debería ser más bien su comida; otro ejemplo son los murciélagos que 'dan de comer' a las mujeres, cuando lo común es que éstas en su condición de seres humanos «den de comer» su sangre a los murciélagos.

Más transparentes en su ditransitividad que los anteriores son los predicados 'entregar' (Luna entrega zapallos maduros a Guarandu), 'pedir' (Machín pide un favor a Wito y Achiote), 'traer' (el joven sol trae carne de cacería a la vieja tigresa) o 'preguntar' (Wito y Achiote preguntan a Machín por qué teje una piola de chambira). En general los predicados ditransitivos son menos frecuentes que los mono-transitivos pero no menos importantes para el análisis en cuanto permiten identificar el tipo de relaciones entre dos personajes.

Los predicados intransitivos, por su parte, involucran solamente un sujeto y en tal virtud señalan experiencias internas o corporales. Tal es el caso de 'llorar' (Lechuza llora cuando es abandonada por Luna); 'dormir' (las mujeres duermen en casa de Murciélago); o 'trinar' (las pajaritas esposas de Garza trinan pero no preparan chicha). Dentro de los predicados intransitivos es importante diferenciar aquellos que son volitivos y no volitivos. Entre los primeros están 'irse' (Luna se va al cielo); 
'quedarse' (Tukiraja se queda con las garzas por un tiempo); ‘subirse' o ‘sentarse' (el joven sol sube/se sienta sobre la palmera chonta). Estos predicados indican la ejecutividad de los personajes, sobre todo cuando son héroes o heroínas culturales. Estos personajes, sin embargo, también pueden estar asociados con predicados intransitivos no volitivos. Los más comunes son 'convertirse' o su equivalente 'transformarse', donde no hay control por parte del sujeto, que por lo tanto pasa a ser únicamente experimentador. Ocurre lo mismo con el predicado 'multiplicarse' (las mazorcas que cortan Wito y Achiote de la chacra de ardilla se multiplican por cientos). Al mismo campo semántico pertenecen los predicados 'descomponerse' (el esposo de Tukiraja se descompone en la hamaca) o 'caerse' (la palmera de chonta se cae sobre el mar). Otros predicados intransitivos no volitivos implican acciones corporales características o adquiridas de un personaje, como 'oler mal' u 'oler bien'; ambos predicados aparecen asociados siempre a personajes opuestos en el pensamiento indígena: Amasanga huele bien; Murciélago huele mal.

Finalmente, existen predicados copulativos que no indican transitividad ni intransitividad sino más bien una característica explícita del personaje. Se trata casi siempre de un verbo copulativo conjugado (ser o estar), seguido de un adjetivo. El caso más frecuente de este tipo de predicados es 'estar embarazada', asociado con un sujeto antropomorfo (la mujer del mito de Tukiraja) o con uno zoomorfo (la tigresa preñada que se salva de ser devorada por las pirañas). Otro ejemplo de predicado copulativo es 'estar casado' o 'estar casada' (Luna está casada con Guarandu).

En muchos casos es posible identificar ciertos predicados que ocurren preferentemente en determinados momentos narrativos. Por ejemplo, un verbo copulativo o existencial es el predicado más común al inicio de un mito, precisamente porque a través de él se establece el status quo del que parte la narración y que termina transformado al final del mito. Por otra parte, el predicado 'encontrar' y su equivalente 'encontrarse con' marcan el cambio de personajes y escenarios o anticipan un nuevo statu quo (Tukiraja encuentra a las mujeres que no saben dar a luz y les enseña cómo hacerlo para que no mueran durante el parto). Asimismo, el predicado 'maldecir' ocurre siempre en los últimos enunciados de un mito y en tal medida se constituye en el acto de habla que funda un nuevo orden del mundo (como cuando el paujil maldice a las mujeres a quedarse a orillas del río y éstas se convierten en pájaros trompeteros).

La que acabamos de presentar es una clasificación nada exhaustiva del copioso conjunto de predicados que encontramos en las mitologías comparadas, quizás la más formal en términos lingüísticos. Alternativamente, es posible agrupar los predicados en aquellos que asocian un sujeto humano o antropomorfo y un objeto zoomorfo o vegetal (el niño Sol come ajíes); o bien aquellos que tienen un contenido télico asociado con un estado final (la tigresa embarazada se salva de morir ahogada).

\section{LUGARES (COMPLEMENTOS) EN LOS MITOS ANDOAS}

Los lugares son el tercer tipo de unidades sígnicas. Los lugares añaden información que puede ser indispensable, como complementar la predicación de verbos de movimiento ('ir', 'llegar', 'subir', 'caminar'); o accesoria, cuando su ausencia no altera la proposición expresada en el mitema. Los lugares identificados en el corpus andoa se encuentran listados en la Tabla 3 (véase Apéndices). En el análisis el monema o palabra que funciona como complemento es el significante y su significado no es otro que el codificado por dicho monema; no obstante, ocasionalmente el significado debe ser explicitado, en cuyo caso hemos colocado entre paréntesis una paráfrasis que vincula el complemento con un sujeto o un predicado. Es posible también que algún predicado aparezca ya con su complemento explícito, sobre todo cuando éste proporciona la información requerida para su correcta interpretación.

Los complementos identificados son menos numerosos que los de las otras categorías (personajes y predicados) no solo en frecuencia (tokens) sino también en variedad (types). En general, los lugares más comunes que aparecen en el corpus andoa son cinco. Con mucho, el más frecuente es la casa. 
Lo interesante, sin embargo, es que el significante 'casa', normalmente asociado con una vivienda humana, se puede utilizar en los mitos también como la morada de un animal (la casa del murciélago), gracias a la naturaleza bifronte de los seres míticos en los tiempos originarios. Por otro lado, la casa no sólo es escenario del sueño y el descanso (Wito y Achiote duermen en la casa de Murciélago), sino también de actividades de vigilia (la tigresa cocina en casa para sus hijos) o incluso de crímenes (los tigres matan a la mujer en la casa de su madre). La casa es además lugar de refugio del individuo, rincón donde guarda secretos y confabula (Guarandu come a solas los zapallos maduros que preparó para su marido), pero también el lugar de los invitados y las relaciones sociales (Amasanga invita a las hermanas a su casa para convertirlas en esposas).

El segundo lugar más referido en el corpus andoa es la selva o el monte. En términos generales, la selva es por excelencia lugar de la cacería (Luna va al monte de cacería), oponiéndose así al espacio doméstico. La selva encierra además varios lugares específicos (la loma, el río). Pero sobre todo, la selva puede tener una dimensión de profundidad y/o lejanía, como sugieren las frases «al interior de la selva» o «dentro de la selva».

La 'chacra', a medio camino entre la selva y el espacio doméstico, es el tercer lugar más frecuente en el corpus andoa. Aunque la chacra es por excelencia el espacio de la mujer, también está asociada con un hombre o con un personaje zoomorfo. La chacra es además el espacio productivo por excelencia. La chacra varía en extensión (la chacra pequeña de un pájaro cualquiera, la chacra grande del paucar, la chacra inmensa de Amasanga), y su extensión es la medida del valor social de un hombre como pretendiente (Amasanga) o como cónyuge (Luna).

Aunque casa, selva y chacra difieren en dimensiones, son todos espacios fijos. Al contrario, el 'camino’ tiene un carácter dinámico. Por un lado coincide con la chacra, gracias a su carácter intermedio entre naturaleza y cultura, a horcajadas entre el espacio salvaje y el espacio doméstico. Por otro lado, el camino se asigna a quien lo recorre con frecuencia o a quien se asocia por alguna virtud (porque conduce a su morada, porque lleva una señal suya): así, el camino de Amasanga o de Murciélago es el camino que lleva a la casa de cada uno, como el camino del paujil o del papagayo es el camino que tiene señales de sus plumas.

Un lugar frecuente en el corpus andoa representa una categoría de objetos que conectan las esferas antitéticas del cielo y la tierra. El primero de estos objetos es el árbol, siempre en forma de palmera, sobre todo chonta (el joven Sol sube al cielo por la chonta). El segundo objeto es la escalera (Luna sube al cielo por una escalera). El vínculo entre cielo y tierra que convierte al árbol en eje del mundo -función simbólica presente en la mitología de todos los pueblos-se matiza en los mitos andoas por su carácter frágil, de suerte que siempre acaba por romperse y su ruptura transforma el mundo en aquel que conocemos hoy: así, los tigres no matan al joven Sol porque la chonta se rompe en dos; y Lechuza no da alcance a Luna porque la escalera se quiebra a medio camino. Sólo por esta ruptura primigenia el joven Sol se convierte en sol, el astro que ilumina el día, y el hombre Luna se convierte en luna, el astro que ilumina la noche.

Aquí termina la identificación de personajes, predicados y lugares del corpus andoa. La tarea ahora consiste en averiguar cuáles de éstos son compartidos por las mitologías de pueblos vecinos, y sobre todo, cómo se han combinado en sus narrativas.

\section{ANÁLISIS COMPARATIVO DE PERSONAJES, TEMAS Y LUGARES CON EL CORPUS PLURI-ÉTNICO}

La identificación de unidades sígnicas (personajes, temas y lugares) se aplicó de la misma manera a todos los 27 mitos que forman parte del corpus pluriétnico. De una primera comparación con el corpus andoa saltan a la vista dos cosas: una es que existe un conjunto amplio de elementos comunes entre ambos corpus; otra es que se muestran diferentes disposiciones (sintaxis) de elementos propios y prestados 
según las mitologías, pero con equivalente o similar valor proposicional, salvo algunas excepciones. A partir de las posibilidades combinatorias enumeradas en $\S 5$, podemos afirmar que se han producido cinco tipos de transformaciones que corresponden a casos de sincretismo e hibridez mitológica ${ }^{14}$.

\section{MITOLOGÍA SINCRÉTICA INDUCIDA POR CONTACTO: NUEVOS TEJIDOS DE PERSONAJES, TEMAS Y LUGARES}

A continuación ofrecemos una discusión de los tres tipos de unidades sígnicas que componen el enunciado de un mitema (personajes, predicados, lugares) en cuanto presentan una mezcla de significantes y significados en nuevas y novedosas combinaciones. Aunque para fines analíticos hemos distinguido aquí entre personajes, temas y lugares, es imposible emprender un análisis de cada uno por separado, por lo que en esta sección realizamos un análisis de las posibilidades combinatorias que dan origen a mitologías sincréticas o híbridas según el caso, enfocándonos unas veces en personajes, otras en temas y otras en lugares.

Los mejores ejemplos de cómo conviven personajes de diferentes mitologías se encuentran al cotejar el mito andoa del sol (Inti Unanchay) con mitos de origen kichwa, arabela o zápara. Nuestro análisis encontró una correspondencia en diferentes grados con los siguientes mitos: en primer lugar, con tres piezas de la mitología kichwa de Pastaza (Nuestros antepasados y el sol; La historia del sol; Los habitantes del monte); en segundo lugar, con tres piezas de la mitología kichwa del Napo (Lucero y Kuyllur, Los primeros hombres de la selva, y Lucero y Kuyllur acaban con los tigres); en tercer lugar, con dos piezas de la mitología zápara (Tsítsano, el héroe cultural; Cuillur y Ducero); y en cuarto lugar, con una pieza de la tradición oral arabela (El cuento del hombre perdido).

Los mitos kichwas de Pastaza incluyen todos los personajes de los mitos andoas, aunque su significado mítico no siempre es el mismo y en ocasiones su sintaxis se presenta en sentido inverso. Por ejemplo, llama la atención que la 'abeja' del mito andoa aparezca también en el mito kichwa, pero no con el significado de 'presa de caza' que tiene en el primero, sino con el de 'picadora venenosa', junto con la serpiente; este cambio en el significado conlleva a su vez un cambio de función gramatical, de modo que la abeja ya no es el objeto paciente de la 'cacería' del niño sol, sino el sujeto agente del predicado 'lamer el veneno'. Esto se muestra claramente en la Tabla 6, donde apreciamos una sintaxis diferente de los elementos míticos, uno de los cuales (abeja) tiene roles semánticos opuestos: mientras en el mito andoa la abeja es un paciente, en el mito kichwa pasa a ser un agente.

Tabla 6. Elementos míticos e inversión sintáctica

\begin{tabular}{|c|c|c|c|c|c|c|}
\hline \multicolumn{2}{|c|}{ ELEMENTOS MÍTICOS } & \multicolumn{5}{|c|}{ SINTAXIS MÍTOLÓGICA ANDOA } \\
\hline FORMA & CONTENIDO & $\mathbf{A}_{\text {AGENTE }}$ & D & B $_{\text {PACIENTE }}$ & & \\
\hline $\mathrm{A}$ & Niño-Sol: (Agente) & \multirow{2}{*}{\multicolumn{5}{|c|}{ SINTAXIS MITOLÓGICA KICHWA }} \\
\hline $\mathrm{B}$ & Abeja: (Agente / Paciente) & & & & & \\
\hline C & Veneno: (Paciente) & & & \multirow{3}{*}{$\mathbf{B}_{\text {AGENTE }}$} & \multirow{3}{*}{$\mathrm{E}$} & \multirow{3}{*}{$\mathrm{C}_{\text {PACIENTE }}$} \\
\hline $\mathrm{D}$ & Cazar (niño-sol, abeja) & & & & & \\
\hline E & Lamer (abeja, veneno) & & & & & \\
\hline
\end{tabular}

Las divergencias en los roles semánticos tienen paralelo en las divergencias en los rasgos semánticos de los argumentos, de suerte que en ciertos casos llegan a ser calcos sintácticos con diferente

14 Estas transformaciones son las siguientes: a) un mitema, uno de cuyos elementos es un significante prestado; c) un mitema, dos de cuyos elementos son significantes prestados; e) un mitema cuyos elementos son todos significantes prestados; g) un mitema con sintaxis prestada, proposición original y significantes prestados; i) un mitema con sintaxis prestada, proposición diferente y significantes propios. 
contenido. Así, por ejemplo, el mito arabela que narra la historia de un hombre que se pierde en el bosque y termina en la casa de los tigres, salvándose de ser devorado al extraer a un tigre una espina de la boca, se corresponde mutatis mutandis con el mito andoa del sol (Inti Unanchay) de acuerdo con otros rasgos semánticos. En primer lugar, mientras en la narración andoa el ser humano es un hombre joven, en el mito arabela se trata de un hombre viejo. En segundo lugar, mientas en el mito andoa el joven sol escapa de ser devorado por los tigres gracias a que sube por la chonta y logra que las espinas de la palmera se introduzcan en las patas de los tigres, en el mito arabela el hombre escapa de ser devorado porque salva a un tigre extirpándole precisamente una espina ${ }^{15}$. Se trata, por tanto, de significantes que se repiten (por ejemplo, ser humano versus tigre) pero con semántica distinta (joven/viejo versus tigre). Esto se muestra esquemáticamente en la siguiente tabla.

Tabla 7. Elementos míticos y calco sintáctico completo

\begin{tabular}{|c|c|c|c|c|c|}
\hline \multicolumn{2}{|c|}{ ELEMENTOS MÍTICOS } & \multicolumn{4}{|c|}{ SINTAXIS MITOLÓGICA ANDOA } \\
\hline FORMA & CONTENIDO & $A_{Y}$ & $\mathrm{~B}$ & PORQUE & $\mathrm{C}_{\mathrm{W}}$ \\
\hline A & hombre: (x, viejo) (y, joven) & \multirow{2}{*}{\multicolumn{4}{|c|}{ SINTAXIS MITOLÓGICA ARABELA }} \\
\hline B & no es devorado & & & & \\
\hline C & espinas: (w, poner) (z, sacar) & $A_{X}$ & $\mathrm{~B}$ & PORQUE & $C_{Z}$ \\
\hline
\end{tabular}

Un caso similar de calco sintáctico completo se encuentra al comparar el mito andoa del niño sol con el mito kichwa Lucero y Kuyllur matan a los tigres. En ambos mitos encontramos a los tigres, primero como devoradores-cazadores-asesinos, luego como víctimas; pero mientras en el mito andoa el niñojoven enfrenta solo a los tigres, en el mito kichwa del Napo son dos los niños-jóvenes que matan a los felinos antropomorfos.

La combinación en una misma sintaxis de personajes, en unos casos equivalentes, en otros apenas similares, puede ser incluso más compleja en cuanto aglutina un número importante de elementos pero también en la medida en que el calco sintáctico sólo es parcial porque falta alguno de los argumentos de la predicación. La comparación de los personajes del mito andoa del sol y del mito zápara de Tsítsano ilustra bien este caso. No sólo que Tsítsano y el niño-joven tienen el mismo estatus de héroes culturales sino que ambos se salvan de ser devorados por los tigres. Sin embargo, mientras el niño-joven mata a los tigres porque es su enemigo, Tsítsano salva a uno de ellos sacándole un erizo que tenía en la boca para hacerse amigo de los tigres. Nótese que la secuencia narrativa incluso es la misma que encontramos en el cuento arabela del hombre perdido, que saca una espina de la boca al hijo de un tigre y se salva así de ser devorado. Más aún, al final del relato, Tsítsano y el hombre perdido vuelven a casa luego de andar por la selva-mundo.

A nivel sintáctico es preciso notar dos cosas. En primer lugar, el mitema andoa carece de un elemento que sí aparece en el mitema zápara (H); en segundo lugar, los conectores son diferentes, de suerte que el elemento E en el mito andoa es la razón que explica la secuencia anterior mientras que D en el mito zápara constituye su propósito o finalidad.

Los personajes míticos no sólo pueden ser diferentes sino, en algunos rasgos semánticos, incluso antitéticos, aunque en otros no lo sean. Tal es el caso de Tsítsano y Tukiraja de las mitologías zápara y andoa, respectivamente. Tsítsano es, en primer lugar, un varón mientras Tukiraja una mujer; pero además, mientras ésta es un ser humano, aquél es un ser sobrehumano. Esta antítesis en la naturaleza de ambos personajes no impide, sin embargo, que ambos compartan los dos macro-predicados de sus

15 Nótese además que el tema 'extrae algo que pica' tiene su equivalente, con personajes distintos, en el enunciado 'la mujer saca la garrapata [que pica] al esposo-tigre' que forma parte del mito zápara de Cuillur y Ducero y se encuentra además en otras versiones en la mitología kichwa de Pastaza. 
Tabla 8. Elementos míticos y calco sintáctico parcial

\begin{tabular}{|c|c|c|c|c|c|c|c|}
\hline \multicolumn{2}{|c|}{ ELEMENTOS MÍTICOS } & \multicolumn{6}{|c|}{ SINTAXIS MITOLÓGICA ANDOA } \\
\hline FORMA & CONTENIDO & A & $\mathrm{F}$ & C & - & PORQUE & $\mathrm{E}$ \\
\hline A & Niño -Sol & \multirow{2}{*}{\multicolumn{6}{|c|}{ SINTÁXIS MÍTOLÓGICA ZÁPARA }} \\
\hline B & Tsítsano & & & & & & \\
\hline C & Tigre(s) & \multirow{6}{*}{ B } & \multirow{6}{*}{ G } & \multirow{6}{*}{ C } & \multirow{6}{*}{$\mathrm{H}$} & \multirow{6}{*}{ PARA } & \multirow{6}{*}{ D } \\
\hline $\mathrm{D}$ & Ser.amigo & & & & & & \\
\hline E & Ser enemigo & & & & & & \\
\hline $\mathrm{F}$ & Matar & & & & & & \\
\hline G & Salvar & & & & & & \\
\hline $\mathrm{H}$ & Espina (sacada) & & & & & & \\
\hline
\end{tabular}

sagas respectivas: a saber, ‘seguir el camino’ y ‘volver a casa'. En efecto, como Tsítsano, Tukiraja es una heroína cultural y, al igual que él, sale de un lugar para volver al punto de donde partió luego recorrer un largo camino. Más todavía, ambos personajes comparten otras actividades características de su estatus: por ejemplo, ambos ‘curan a los tigres extirpándoles espinas'; ambos 'enseñan', Tsítsano a los peces motauri a defecar, Tukiraja a las mujeres a dar a luz.

En el mismo contexto, no obstante, sus acciones también son diferentes: Tukiraja no mata a la tortuga lunareja con quien se encuentra, pero Tsítsano sí. Más importante aún es la direccionalidad del viaje de ambos héroes culturales. El itinerario de Tukiraja se desarrolla explícitamente en un eje vertical tierra-cielo-tierra: Tukiraja es llevada primero por un ave carroñera al lugar donde está su esposo muerto; luego sube al cielo a través de una palmera; y finalmente baja a la tierra en un bolso tejido por el paujil. La ruta de Tsítsano, por el contrario, se desplaza a lo largo de un eje horizontal: «andando de casa en casa, de comunidad en comunidad». En ambos casos, sin embargo, existe una circularidad explícita que se cierra con la vuelta al lugar de origen. Esto demuestra que los personajes, los predicados y los lugares pueden agruparse en cada caso siguiendo sintaxis opuestas. El gráfico 1 permite una visualización esquemática de lo dicho a propósito de los itinerarios de ambos héroes culturales.

No deja de llamarnos la atención el hecho de que el personaje de Tukiraja aparezca sólo en la mitología andoa y en ninguna otra de un grupo zaparoano, donde los héroes culturales son siempre

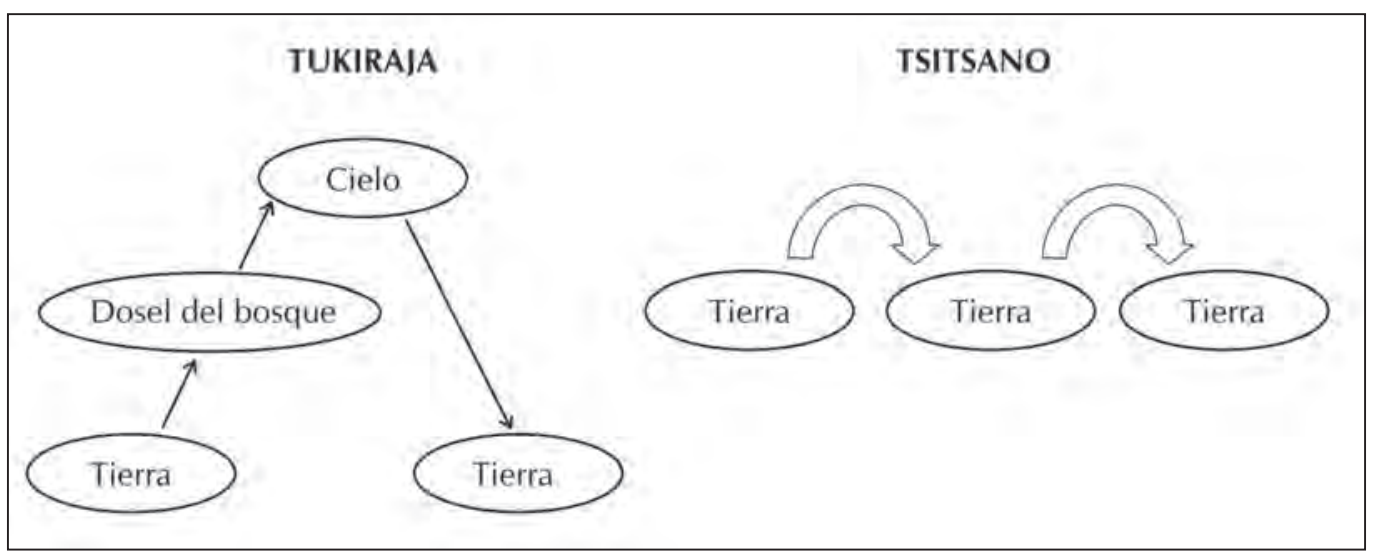

Gráfico 1. Direccionalidad del desplazamiento de los héroes culturales andoa y zápara 
varones. La única mitología de un pueblo de contacto donde existe una semejanza de personaje ('mujer') pero también de macro-predicación (enseñanza-curación) es la saga jíbara de Nunkui. En ella Nunkui enseña a las mujeres la cerámica y entrega a su hija para que 'llame' a los alimentos ${ }^{16}$. Dado el contacto entre andoas y achuar en el contexto de las misiones de Juanjiris (Ecuador) y Santo Tomás de Andoas (Perú), nos parece muy probable que Tukiraja sea un significante tomado de la mitología shuar-achuar que se ha llenado con un significado cultural andoa, aunque en uno y otro caso no dejen de encontrarse significados y predicaciones opuestos: Nunkui y su hija son divinidades creadoras, Tukiraja y su hijo son seres humanos; Tukiraja se queda sin esposo y ayuda a una mujer casada, Nunkui no es casada pero ayuda a una mujer abandonada por su esposo.

Los tres mitos restantes que guardan equivalencia mínima y parcial con los temas del mito de Tukiraja son uno arabela (El hombre que se perdió en el bosque) y dos kichwas de Pastaza (La historia del sol, Los habitantes del monte). En el caso del mito arabela del hombre perdido, encontramos dos mitemas que comparten sus predicados en ambas mitologías, a saber, 'sacar la espina al tigre' y 'volver a casa'. En el caso del mito kichwa sobre el sol existe al menos un mitema en común con el relato de Tukiraja, 'encontrar la casa de los tigres'. Sin embargo, como en el caso de Tsítsano y Tukiraja, una diferencia fundamental con los mitos arabela y kichwa es que en ellos el personaje es masculino.

La direccionalidad expresada predicativamente a través de verbos de movimiento, como en el caso de los itinerarios de Tsítsano y Tukiraja, se articula en matrices topológicas específicas que corresponden en la gramática a sendos complementos de lugar, siendo los principales, la casa, la selva, la chacra, el camino y el árbol-escalera. Todos ellos aparecen en el corpus pluri-étnico, pero con matices diferentes a nivel del significante y del significado.

La escalera del mito andoa de la luna es la matriz de conexión entre el cielo y la tierra (axis mundi, igual que el árbol). Del mismo modo, en dos mitos naporunas la escalera cumple igual función conectora pero su naturaleza es diferente: en el mito de Lucero y Kuyllur acaban con los tigres, es una raíz de yutzu (Calliandra angustifolia); en el mito de Killa y Filuku, el amor de la luna, la escalera está hecha de flechas de pindo (Butia capitata). Esto significa que el sintagma nominal 'escalera' puede ser cualificado ('larga', 'angosta', etc.) o bien reemplazado por un objeto vegetal que hace las veces de escalera (una raíz, un bejuco, etc.).

Lo dicho con respecto a la escalera vale también para el árbol. Se califica el árbol, por ejemplo, según la altura ('árbol alto'), o bien se especifican con un sintagma nominal adjunto los dos extremos en el eje vertical: la raíz o la base, que roen y cavan las ardillas y los armadillos para derribar la chonta y ayudar a los tigres a atrapar al niño sol; y la punta o la copa, a donde llega únicamente el niño sol para convertirse en astro rey, o a donde sube la Tukiraja para no ser vista por los tigres y salvar su vida y la de su hijo.

Es importante señalar, a propósito de los complementos, que su posición es mucho más fija dentro del enunciado y que su significado debe decodificarse siempre a partir de su relación con las dos unidades significativas principales (temas y personajes). Esto implica que los complementos muy a menudo están asociados con un tipo específico de predicados y sujetos y en tal medida su función combinatoria es reducida. Hasta aquí el análisis comparativo.

En resumen, con respecto a los nuevos de tejidos de personajes, temas y lugares hemos visto que existe desde un calco sintáctico total o parcial, con elementos diferentes o equivalentes, a una sintaxis invertida de algún elemento del mitema. No hemos podido dar con una sintaxis invertida para todos los elementos, como sugiere Lévi-Strauss para los Mandan y los Hidatsa (cf. supra). La razón posiblemente se halle en que los grupos de este estudio reconstruyen sus mitologías con elementos propios, similares en algunos casos, pero no exactamente antitéticos porque pertenecen a un mismo tronco no figura propiamente como un sujeto agente, al menos en la versión recogida por nosotros. 
etnolingüístico y posiblemente su afán de distinción no es extremo. Al respecto, sin embargo, resulta interesante que sean precisamente el mito andoa del niño sol y el mito arabela del hombre perdido, ambos zaparoanos, los que contrastan diametralmente sus significados pero no su sintaxis; esto sugiere que se ha utilizado el mismo esquema mítico con elementos culturales propios de cada grupo.

\section{ConClusión}

La evidencia obtenida de la comparación del corpus andoa con el corpus pluri-étnico demuestra que estamos ante un conjunto de mitos que no sólo beben de una misma fuente, sino lo más importante, que cada narrativa es potencialmente fuente de otra, proporcionando la forma (significante) y la esencia (significado) de los mitos así como el orden de cada unidad dentro del enunciado y el orden de los enunciados (Lévi-Strauss 1987: 248). Creemos haber demostrado así que los mitos, al estar hechos de palabras, se comportan como las lenguas en contacto, esto es, intercambiando material según las condiciones sociohistóricas de sus hablantes y negociando la entrada de nuevas realidades a la cosmovisión tradicional.

La metodología de esta investigación siguió a grandes rasgos el análisis estructural por ser sistemático y útil para el estudio narrativo del mito. Sin embargo, nuestro enfoque va más allá de lo puramente estructural: apunta hacia lo histórico y social del mito, y para ello toma como punto de partida el concepto de contacto entre grupos etnolingüísticos diferentes en áreas culturales. Estamos seguros de que la conjugación de una metodología estructuralista con una perspectiva histórica puede reactivar el interés en el estudio del mito hoy en día, época de profundos y amplios contactos entre grupos humanos a lo largo y ancho del planeta, pero también época en que reciclamos el pasado en el presente para construir y reconstruir identidades.

\section{BibliografíA}

AMODIO, Emanuele

1989 «Mitología sincrética makuxi». En: VV.AA. Las Religiones Amerindias 500 Años Después. Quito: Editorial Abya Yala, pp. 91-136

CABODEVILLA, Miguel Ángel

1999 Los Huaorani en la historia de los pueblos del Oriente. Quito: Cicame.

COHEN, Percy

1969 «Theories of Myth», Man, New Series, 4(3): 337-353, Sept 1969.

DÁVILA Jacinto

1937 «Documentos para la historia de las Misiones Dominicanas en el Oriente-Pastaza», Oriente Dominicano, 10(56-57): 184-198, 211-222.

EASTMANN, Elizabeth

2008 Relatos y Leyendas de los Iquitos. Comunidades y Culturas Peruanas No.32. (edición lectura), Lima: ILV. $62 \mathrm{p}$.

FAST, Gerard

1976 Cuentos folklóricos de los achual. Comunidades y Culturas Peruanas No. 3, Lima: ILV. 248 p.

FERRARO, Guido

2001 Il linguaggio del mito. Roma: Meltemi Editore, 360 p.

GOLDARAZ, José Miguel

2004 Mitos y tradiciones de los Naporuna. s/e. 224 p.

GÓMEZ RENDÓN, Jorge

2013 «Los andoas: construcción histórica y narrativa de su identidad». Revista del Consejo Nacional de Cultura, 21: 37-104.

2010 Andoa-Kichwa Shimiyuk Panka. [Diccionario bilingüe shimigae-kichwa]. Quito: IBIS-Dinamarca. 
HINSON, Mary Elizabeth

2008 Cuentos folklóricos candoshi. Comunidades y Culturas Peruanas No. 4, Lima: ILV. 54 p.

INSTITUTO LINGÜÍSTICO DE VERANO

1968 Pueya Pohuatasano. [Cuentos Arabelas]. Cartilla 10. Lima: Ministerio de Educación y Cultura.

1968 Zitamina Koko. [Leyendas de los antepasados shapras]. Candoshi 1. Lima: Ministerio de Educación y Cultura.

LÉVI-STRAUSS, Claude

1997 [1968] El origen de las maneras de mesa. Mitológicas Vol. 3. México: Siglo XXI Editores. 495 p.

1987 [1971] Antropología Estructural II. México: Siglo XXI Editores. 352 p.

1972 [1966] De la miel a las cenizas. Mitológicas Vol. 2. México: FCE. 438 p.

1972 [1964] Lo crudo y lo cocido. Mitológicas Vol. 1. México: FCE. 438 p.

1976 [1971] El hombre desnudo. Mitológicas Vol. 4. México: Siglo XXI. 697 p.

1955 «The Structural Study of Myth». The Journal of American Folklore, 68(270): 428-444.

LEWIS, M. Paul (ed.)

2009 Ethnologue: Languages of the World, Sixteenth edition. Dallas, Tex.: SIL International. [En línea]. <http://www.ethnologue.com/>.

MEJÍA, Humberto

1927 «Rasgos históricos acerca del pueblo de Pacayacu», Oriente Dominicano, 2: 32-34.

MELETINSKI, Eeazar

2001 [1993] El mito: literature y folklore. Madrid: Ediciones Akal. 359 p.

MOYA, Alba

2007 Los Aritiakus. Hijos e hijas del mono colorado. Quito: UNESCO. 302 p.

NARANJO, Marcelo

1977 «Zonas de refugio y adaptación étnica en el Oriente». En: Marcelo F. Naranjo (comp.), Temas sobre la continuidad y adaptación cultural ecuatoriana. Quito: PUCE.

PAYNE, David

1984 «Evidence for a Yaguan-Zaparoan linguistic connection», SIL-WP-UND 28, pp. 131-156.

REEVE, Mary-Elizabeth

2002 Los Quichua del Curaray. El proceso de formación de la identidad. Quito: Ediciones Abya Yala.

SPRUCE, Richard

1908 Notes of a Botanist on the Amazon and Andes. Londres: Macmillan and Co. Limited.

STARK, Louisa R

1985 «Indigenous languages of Lowland Ecuador». En: Harriet E. Manelis Klein \& Louisa R. Stark (eds.), South American Indian languages. Retrospect and prospect: 157-193. Austin: University of Texas Press

STEWARD, Julian $\mathrm{H}$.

1948 «Tribes of the Montaña: an Introduction». En Julian H. Steward. Handbook of South American Indian, Vol. 3, Washington D.C: United State Government Printing Office, pp. 507-534

TUGGY, John

2008 Textos candoshi. Datos Etnolingüísticos No. 40. Lima: ILV.

WATERS, Anne-Lou H.

1998 Cuentos folklóricos de los quechuas del Pastaza. Comunidades y Culturas Peruanas No. 28, Lima: ILV. $364 \mathrm{p}$.

WHITTEN, Norman E. Jr.

1976 Sacha Runa: Ethnicity and Adaptation of Ecuadorian Jungle Quichua. Urbana: University of Illinois Press. 